\title{
Systematic Trial for Evaluating Docetaxel in a Human Prostate Cancer Cell DU145 Xenograft Model
}

\author{
MIYUKI MABUCHI ${ }^{1,2}$, MASAHIRO UEDA $^{1,2}$, YURI YOSHIDA ${ }^{1,2}$, KOTA HORIIKE $^{1,2}$, KENTA YAMAOKA $^{1,2}$, \\ SYUHEI NAKAO ${ }^{1,2}$, TADASHI SHIMIZU ${ }^{1,2}$, YUKO UEDA ${ }^{3}$, KAZUTAKE TSUJIKAWA $^{3}$ and AKITO TANAKA ${ }^{1,2}$ \\ ${ }^{1}$ School of Pharmacy, Hyogo University of Health Sciences, Kobe, Japan; \\ ${ }^{2}$ Laboratory of Chemical Biology, Advanced Medicinal Research Center, \\ Hyogo University of Health Sciences, Kobe, Japan; \\ ${ }^{3}$ Laboratory of Molecular and Cellular Physiology, Graduate School of \\ Pharmaceutical Sciences, Osaka University, Suita, Japan
}

\begin{abstract}
The inhibitory activities of docetaxel at a wide range of doses (0.1-10 $\mathrm{mg} / \mathrm{kg}$; subcutaneously (s.c.), once/week) in nude mice bearing a human prostate cancer cell (DU145), xenograft model with implantation of DU145 cells or a DU145 solid tumor were examined. This systematic trial demonstrated that (i) docetaxel was more effective in the xenograft model formed by implantation of DU145 cells than in the solid DU145 tumor; (ii) administration of $2.5 \mathrm{mg} / \mathrm{kg}$ docetaxel was the critical dose because inhibitory activities were not observed at $2.5 \mathrm{mg} / \mathrm{kg}$, while they were noted at $5 \mathrm{mg} / \mathrm{kg}$ and $10 \mathrm{mg} / \mathrm{kg}$ in both implantation approaches; (iii) edema-like effects (plump body shape and legs) were observed in both groups at $2.5 \mathrm{mg} / \mathrm{kg}$ and the tumor sizes, often increased by blood plasma and other fluids, as well as body weights were higher than at other doses; and (iv) suppression of body weight gain was observed at $10 \mathrm{mg} / \mathrm{kg}$ docetaxel.
\end{abstract}

Prostate cancer is one of the leading causes of male mortality due to cancer and its prevalence is now increasing; therefore, the development of effective new drugs is required (1). Androgen ablation therapy is usually effective for this cancer at an earlier stage because the tumors typically depend on androgen for development and growth at that period. However, alternative drugs are needed to treat androgenindependent tumors (2). Docetaxel (DTX) is a taxane derivative, widely used anti-microtubule anti-cancer drug,

Correspondence to: Akito Tanaka, School of Pharmacy, Hyogo University of Health Sciences, 1-3-6 Minatojima, Chuo-ku, Kobe 650-8530, Japan. Tel: +81 783043067, Fax: +81 783042767, e-mail: tanaka-a@huhs.ac.jp

Key Words: Docetaxel, DU145, xenograft model, nude mice, anticancer drug, dose-dependency, side-effects. and an effective chemotherapeutic drug for first-line treatment of hormone-refractory prostate cancer (3). Therefore, combination and comparison studies in vitro and in vivo with DTX are vital for developing novel anti-prostate cancer agents.

DU145 is a human hormone-independent prostate cancer cell line widely used for evaluating novel anti-prostate cancer agents (4). The inhibitory activity of DTX against DU145 in vitro exhibited a half-maximal inhibitory concentration $\left(\mathrm{IC}_{50}\right)$ of $1.1 \mathrm{nM}$ (Figure 1). A xenograft model of DU145 tumor growth in nude mice is useful for evaluating agents that can treat hormone-refractory prostate cancer. However, the dose-dependence of DTX in such xenograft mice has not been reported, even though it is vital for the screening and development of novel anti-prostate cancer drugs. We report the results of a systematic trial on growth suppression of implanted DU145 tumors and sideeffects with DTX in a wide range $(0.1-10 \mathrm{mg} / \mathrm{kg}$; subcutaneously (s.c.); in a week) in two models, a xenograft model formed by implantation of a mixture of DU145 cells and Matrigel ${ }^{\mathrm{TM}}$ and a model formed by implantation of solid DU145 tumors (Figure 2).

\section{Materials and Methods}

Cell line and cell culture. The human prostate cancer cell line DU145 was supplied from Riken BioResource Center (\#RCB2143), Tsukuba, Japan. The cell line was maintained in RPMI 1640 supplemented with $10 \%$ fetal bovine serum, 100 units $/ \mathrm{ml}$ penicillin and $100 \mu \mathrm{g} / \mathrm{ml}$ streptomycin at $37^{\circ} \mathrm{C}$ in a humidified atmosphere containing $5 \% \mathrm{CO}_{2}$.

Inhibition of DU145 growth in vitro by DTX. DTX (\#D4102) was purchased from Tokyo Chemical Industry Co., Ltd. Tokyo, Japan. DU145 was seeded at a density of 1,700 cells/ well on 96-well plates (Sumitomo Bakelite Co., Ltd., Tokyo, Japan). The next day, DTX was added to each well at concentrations of $0,0.4,0.6,0.8,1$ and $2 \mathrm{nM}$ (final in $0.1 \%$ DMSO). After 3 days, the numbers of viable 
cells were determined using WST-1 (\#W201; 2-(4-Iodophenyl)-3-(4nitrophenyl)-5-(2,4-disulfophenyl)-2H-tetrazolium monosodium salt) and 1-methoxy-5-methylphenazinium methylsulfate (\#M003), which were purchased from Dojindo Laboratories (Kumamoto, Japan). After the addition of WST-1, the absorbance was measured at 450 $\mathrm{nm}$ with $630 \mathrm{~nm}$ as a reference wavelength using a Versa Max reader (Molecular Devices, Tokyo, Japan).

Xenograft model formed by implantation of a mixture of DU145 cells and Matrigel $^{T M}$ (Figure 2A). Male nude BALB/c mice were purchased from Japan SLC Inc. (Shizuoka, Japan). The animals were housed in constant temperature and humidity conditions and fed a standard diet with water ad libitum. Our institutional animal care committee approved all animal experiments. Male nude mice were subcutaneously implanted with approximately $100 \mu \mathrm{l}$ of $8 \times 10^{6}$ DU145

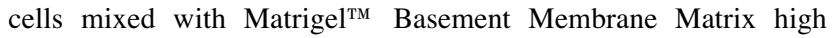
Concentration (Matrigel ${ }^{\mathrm{TM}}$ ) (\#354248; Corning, Tokyo, Japan) into the right flank. When the estimated tumor volume reached approximately $200 \mathrm{~mm}^{3}$, mice bearing established tumors were randomized into five treatment groups (vehicle; 1, 2.5, 5 and $10 \mathrm{mg} / \mathrm{kg}$, DTX; $\mathrm{n}=6$ for each group) with an almost equivalent average body weight. The mice were subcutaneously treated with each concentration of DTX in PEG300 once per week and observed for 26 days. The tumor volumes (V) were calculated by caliper measurements of the width (W) and length (L) of each tumor using the formula: $\mathrm{V}=\mathrm{W} \times \mathrm{W} \times \mathrm{L} / 2$.

Xenograft model formed by implantation of a solid tumor of DU145 (Figure $2 B$ ). Male nude mice were subcutaneously implanted with approximately $100 \mu \mathrm{l}$ of $8 \times 10^{6}$ DU145 cells mixed with Matrigel ${ }^{\mathrm{TM}}$ into the right flank. The tumor was obtained from the mice and split into pieces (particle sizes of approximately $3 \mathrm{~mm} \times 3 \mathrm{~mm} \times 3 \mathrm{~mm}$ ) and then subcutaneously implanted into 5-week-old nude mice. When the estimated tumor volume reached ca. $100 \mathrm{~mm}^{3}$, mice bearing established tumors were randomized into 8 treatment groups (vehicle; $0.1,0.5,0.75,1.0,2.5,5.0$ and $10 \mathrm{mg} / \mathrm{kg} \mathrm{DTX;} \mathrm{n}=5$ for each group) with an almost equivalent average of body weight and tumor volumes. The mice were subcutaneously treated with each concentration of DTX in $0.5 \%$ methylcellulose (MC) for 32 days once per week. Tumor volumes and body weight were periodically measured. Animals were sacrificed after 32 days and the weights of the tumor, liver, kidney and spleen were measured. Blood was collected from the abdominal vein with heparin as an anticoagulant and the plasma was obtained by centrifugation. The concentrations of serum glutamic-oxaloacetic transaminase (GOT), glutamicpyruvic transaminase (GPT), creatinine and blood urea nitrogen (BUN) were measured using commercially available kits (Transaminase CII Test WAKO \#431-30901, LabAssay Creatinine \#290-65901, L type WAKO UN \#410-55391 \#416-55951; WAKO Pure Chemical Industries, Ltd., Osaka, Japan).

Statistical analysis. The results are shown as the means \pm standard error (SE) of each group and were analyzed for statistical significance using Student's $t$-test compared with vehicle control.

\section{Results}

Inhibition of DU145 growth in vitro by DTX. The inhibitory activity of DU145 cell growth by DTX was estimated (Figure 1). The $\mathrm{IC}_{50}$ value was $1.1 \mathrm{nM}$ in this study after $72 \mathrm{~h}$ of drug exposure, which was approximately in agreement with a

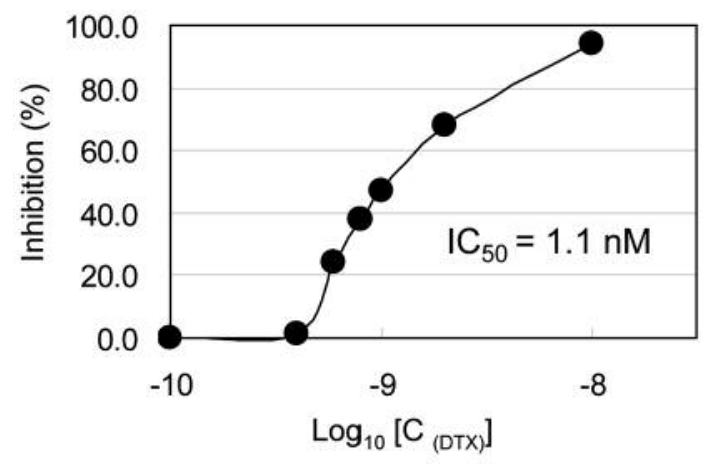

Figure 1. Inhibition of DU145 growth by docetaxel in vitro. DTX, docetaxel; $I C_{50}$, half maximal inhibitory concentration.

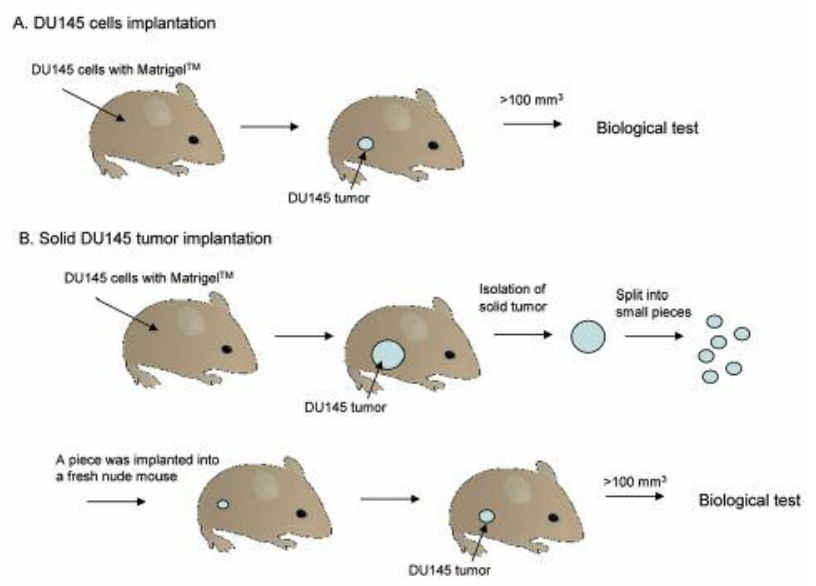

Figure 2. The two xenograft models evaluated in this study.

previous report's $\mathrm{IC}_{50}$ values of $0.47 \mathrm{nM}(4)$ and $1.1 \mathrm{nM}(5)$.

Suppression of xenograft DU145 tumor by DTX. There were two xenograft murine models bearing DU145 cells (Figure 2). First, the inhibitory effect of DTX on DU145 tumor growth after subcutaneous implantation with DU145 cells mixed with Matrigel ${ }^{\mathrm{TM}}$ was examined (Figure 2A). Vehicle or DTX $(1,2.5,5$ and $10 \mathrm{mg} / \mathrm{kg})$ was subcutaneously administered once a week for 26 days and the tumor volume $\left(\mathrm{mm}^{3}\right)$, as well as body weight $(\mathrm{g})$, were periodically measured (Figure 3; Tables I, II and III). The tumor growth was slower than control growth at doses of 1.0, 5.0 and $10 \mathrm{mg} / \mathrm{kg}$ DTX, though tumor growth was accelerated at $2.5 \mathrm{mg}$. Tumor sizes at $10 \mathrm{mg} / \mathrm{kg}$ DTX were significantly reduced within a few days $(p<0.05$ by Student's $t$-test). Interestingly, tumors in the $2.5 \mathrm{mg} / \mathrm{kg}$ DTX-group were often filled with liquid matter, such as blood plasma and sometimes blood, while tumors at the other doses consisted of cells (Figure 3D). The body weights of mice were reduced 
A. Tumor volume

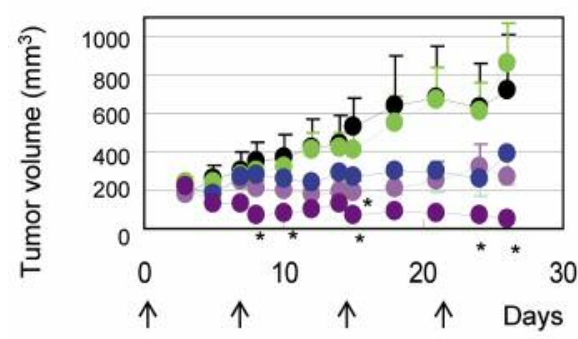

C. Body weight

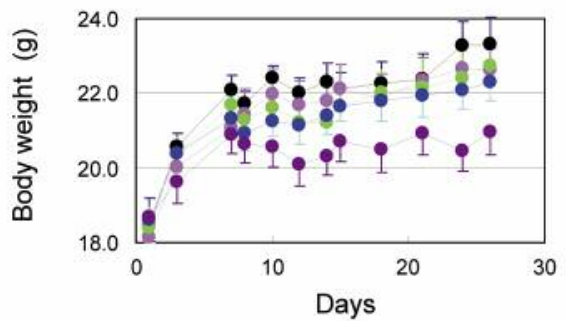

B. Relative tumor volume

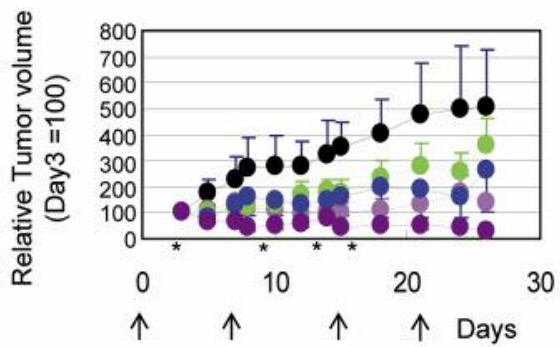

D. Comparison of normal tumor and that fulfilled with plasma

Normal tumor

Tumor fulfilled with plasma and liquid matter
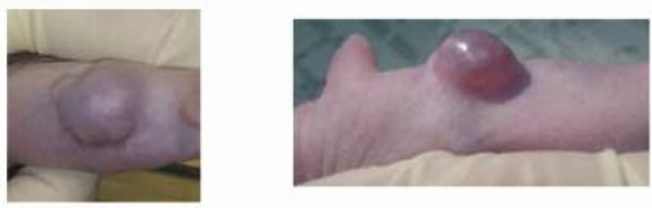

Figure 3. Suppression of DU145 cells growth in vivo by docetaxel. Male nude mice were subcutaneously implanted with approximately $8 \times 10^{6}$ DU145 cells mixed with Matrigel ${ }^{T M}$ into the right flank. When the estimated tumor volume reached almost $200 \mathrm{~mm}^{3}$, docetaxel was subcutaneously administered once a week after randomization into 5 treatment groups (black: vehicle, pink: 1, green: 2.5, blue: 5 and purple: $10 \mathrm{mg} / \mathrm{kg}$ docetaxel, $n=6$ for each group). A: Tumor volumes were calculated by caliper measurements of the width $(W)$ and length $(L)(V o l u m e=W \times W \times L / 2)$. B: Relative tumor volume (volumes at day 3 are 100). C. Body weights. D. Edematous phenomena in tumors were observed with $2.5 \mathrm{mg} / \mathrm{kg}$ docetaxel. All values were tabulated in Tablew I-III. Each value represents the mean \pm SE of six mice. ${ }^{*} p<0.05$ comparison with control by Student's $t$-test.

A. Tumor volume

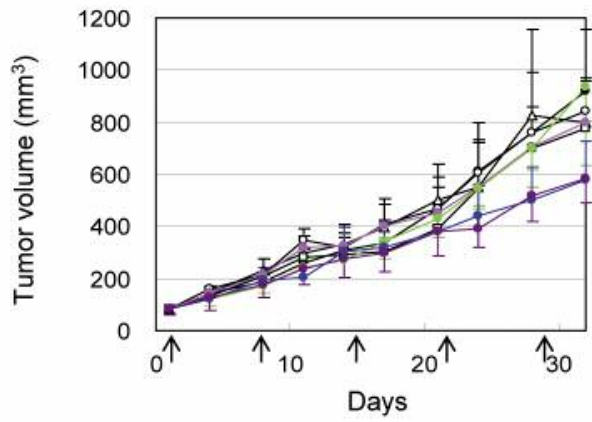

C. Body weight

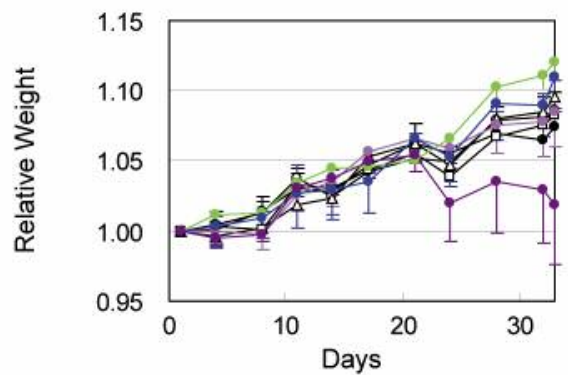

B. Relative tumor volume

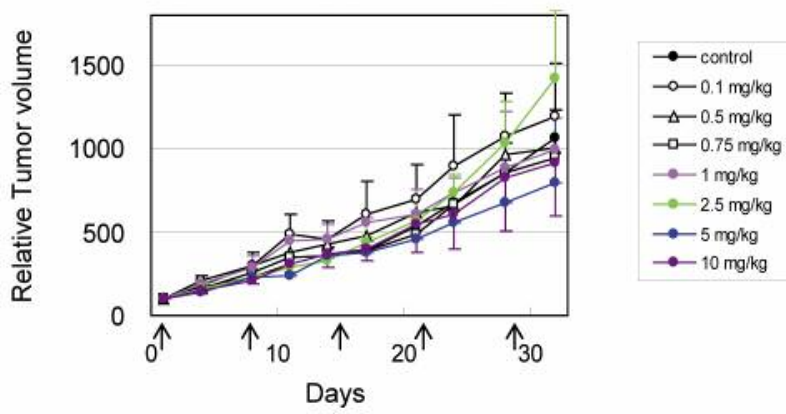

D. Edematous body at DTX $(2.5 \mathrm{mg} / \mathrm{kg})$

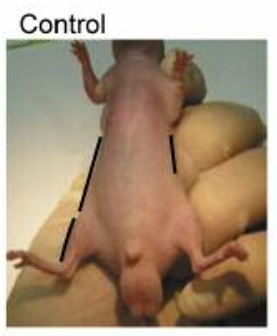

DXT $(2.5 \mathrm{mg} / \mathrm{kg})$

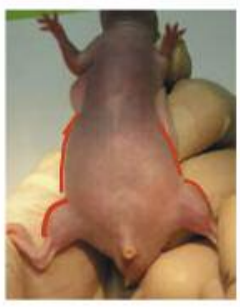

Figure 4. Suppression of DU145 cell block growth in vivo by docetaxel. Male nude mice were subcutaneously implanted with solid tumor into the right flank. When the estimated tumor volume reached almost $100 \mathrm{~mm} 3$, docetaxel was subcutaneously administered once a week after randomization into 8 treatment groups (black closed circle: vehicle, black open circle: $0.1 \mathrm{mg} / \mathrm{kg}$, black open triangle: $0.5 \mathrm{mg} / \mathrm{kg}$, black open square: $0.75 \mathrm{mg} / \mathrm{kg}$, pink:1, green: 2.5 , blue: 5 and purple: $10 \mathrm{mg} / \mathrm{kg}$ docetaxel, $n=6$ for each group). A: Tumor volumes were calculated by caliper measurements of the width $(W)$ and length $(L)($ volume $=W \times W \times L / 2) . B$ : Relative tumor volume (Volume at day $1=100)$. C: Body weight. D: Edematous phenomena were observed in mice with $2.5 \mathrm{mg} / \mathrm{kg}$ docetaxel. All values were tabulated in Tables I-III. Each value represents the mean \pm SE of five mice. 
Table Ia. Tumor size $\left(\mathrm{mm}^{3}\right)$, averaged tumor size and standard error (SE) values.

\begin{tabular}{|c|c|c|c|c|c|c|c|c|c|c|c|c|c|}
\hline \multirow[t]{2}{*}{ Dosage } & \multirow[t]{2}{*}{ Animal No. } & \multicolumn{12}{|c|}{ Days } \\
\hline & & 3 & 5 & 7 & 8 & 10 & 12 & 14 & 15 & 18 & 21 & 24 & 26 \\
\hline \multirow[t]{8}{*}{ Vehicle } & 1 & 35.0 & 130.6 & 228.7 & 299.4 & 295.3 & 232.2 & 323.4 & 270.1 & 327.7 & 484.1 & 586.625 & 529.83 \\
\hline & 2 & 125.4 & 247.2 & 207.6 & 241.8 & 320.6 & 458.6 & 468.5 & 517.6 & 420.2 & 458.6 & 386.6 & 403.5 \\
\hline & 3 & 277.3 & 261.8 & 480.3 & 588.1 & 616.5 & 839.8 & 836.4 & 1127.1 & 1822.5 & 1822.5 & 1565.0 & 1909.3 \\
\hline & 4 & 121.3 & 238.3 & 149.4 & 135.0 & 118.0 & 0.0 & 0 & 245.1 & 184.6 & 78.0 & 110.9 & 143.7 \\
\hline & 5 & 352.5 & 583.2 & 689.1 & 740.1 & 807.4 & 878.4 & 870.9 & 849.4 & 957.6 & 1112.9 & 1029.6 & 1233.9 \\
\hline & 6 & 171.2 & 85.2 & 74.0 & 81.9 & 54.7 & 127.1 & 142.9 & 144.9 & 107.2 & 98.8 & 71.5 & 78.8 \\
\hline & Average & 180.4 & 257.7 & 304.8 & 347.7 & 368.7 & 422.7 & 440.4 & 525.7 & 636.6 & 675.8 & 625.0 & 716.5 \\
\hline & SE & 47.2 & 71.3 & 95.1 & 106.6 & 118.7 & 151.1 & 146 & 158.7 & 266.9 & 275.7 & 236.4 & 292.0 \\
\hline DTX & 7 & 151.2 & 133.2 & 180.8 & 81.5 & 0.0 & 0.0 & 0.0 & 0.0 & 0.0 & 0.0 & 0.0 & 0.0 \\
\hline \multirow[t]{7}{*}{$1 \mathrm{mg} / \mathrm{kg}$} & 8 & 257.1 & 163.3 & 325.8 & 239.6 & 250.0 & 249.7 & 256.6 & 259.2 & 301.2 & 443.8 & 455.2 & 490.4 \\
\hline & 9 & 151.2 & 263.8 & 316.9 & 254.6 & 365.1 & 158.8 & 200.9 & 154.9 & 202.0 & 155.7 & 250.3 & 0.0 \\
\hline & 10 & 162.5 & 174.6 & 221.4 & 202.6 & 198.6 & 292.5 & 282.0 & 371.3 & 386.9 & 502.2 & 683.6 & 619.5 \\
\hline & 11 & 194.4 & 290.4 & 372.0 & 346.4 & 292.5 & 310.3 & 296.5 & 337.9 & 372.0 & 427.6 & 533.0 & 507.8 \\
\hline & 12 & 165.3 & 154.7 & 100.0 & 143.0 & 83.9 & 70.7 & 98.8 & 0.0 & 0.0 & 0.0 & 0.0 & 0.0 \\
\hline & Average & 180.3 & 196.7 & 252.8 & 211.3 & 198.3 & 180.3 & 189.1 & 187.2 & 210.4 & 254.9 & 320.3 & 269.6 \\
\hline & SE & 16.7 & 26.3 & 42.1 & 37.6 & 55.3 & 51.4 & 47.9 & 66.6 & 71.7 & 94.2 & 116.3 & 121.9 \\
\hline DTX & 13 & 328.1 & 292.5 & 249.2 & 309.3 & 346.8 & 470.5 & 386.6 & 414.1 & 506.0 & 738.1 & 542.6 & 724.7 \\
\hline \multirow[t]{7}{*}{$2.5 \mathrm{mg} / \mathrm{kg}$} & 14 & 245.5 & 205.8 & 346.8 & 406.5 & 341.2 & 358.4 & 363.4 & 392.1 & 597.9 & 677.2 & 608.6 & 1106.6 \\
\hline & 15 & 203.7 & 253.6 & 295.3 & 246.1 & 239.6 & 409.6 & 476.6 & 407.2 & 636.3 & 630.6 & 649.4 & 864.6 \\
\hline & 16 & 209.1 & 259.6 & 417.9 & 503.6 & 576.0 & 778.5 & 769.2 & 893.8 & 1069.2 & 1351.7 & 1224.9 & 1580.1 \\
\hline & 17 & 171.0 & 196.6 & 103.2 & 113.8 & 89.9 & 73.6 & 180.8 & 88.9 & 27.6 & 40.3 & 69.8 & 36.1 \\
\hline & 18 & 293.5 & 233.3 & 287.6 & 226.8 & 303.2 & 372.0 & 358.4 & 271.1 & 477.9 & 577.4 & 559.8 & 844.0 \\
\hline & Average & 241.8 & 240.2 & 283.3 & 301.0 & 316.1 & 410.4 & 422.4 & 411.2 & 552.5 & 669.2 & 609.2 & 859.4 \\
\hline & SE & 24.3 & 14.6 & 43.2 & 56.5 & 64.9 & 92.5 & 79.7 & 109.1 & 136.5 & 170.9 & 150.4 & 206.3 \\
\hline DTX & 19 & 196.5 & 272.0 & 194.5 & 200.7 & 250.5 & 257.4 & 252.3 & 211.3 & 247.6 & 245.2 & 267.1 & 353.0 \\
\hline \multirow[t]{7}{*}{$5 \mathrm{mg} / \mathrm{kg}$} & 20 & 98.4 & 95.0 & 280.9 & 502.2 & 406.8 & 359.7 & 346.6 & 525.1 & 734.5 & 715.5 & 534.6 & 1026.7 \\
\hline & 21 & 316.0 & 257.4 & 317.2 & 271.8 & 144.5 & 146.2 & 270.7 & 133.2 & 50.4 & 137.9 & 95.0 & 148.8 \\
\hline & 22 & 280.8 & 361.3 & 520.7 & 541.0 & 509.9 & 523.4 & 520.7 & 486.0 & 567.6 & 604.7 & 482.4 & 688.2 \\
\hline & 23 & 261.8 & 104.0 & 195.3 & 81.8 & 106.4 & 73.7 & 175.7 & 197.6 & 70.0 & 58.7 & 90.4 & 132.9 \\
\hline & 24 & 191.5 & 0.0 & 105.9 & 102.5 & 158.9 & 74.1 & 158.1 & 93.3 & 108.0 & 63.5 & 81.6 & 0.0 \\
\hline & Average & 224.2 & 181.6 & 269.1 & 283.3 & 262.8 & 239.1 & 287.4 & 274.4 & 296.3 & 304.3 & 258.5 & 391.6 \\
\hline & SE & 32.0 & 55.6 & 58.7 & 80.5 & 66.1 & 72.8 & 54.4 & 75.3 & 117.6 & 116.7 & 84.2 & 160.4 \\
\hline DTX & 25 & 409.9 & 170.7 & 242.5 & 0.0 & 0.0 & 0.0 & 0.0 & 0.0 & 0.0 & 0.0 & 0.0 & 0.0 \\
\hline \multirow[t]{7}{*}{$10 \mathrm{mg} / \mathrm{kg}$} & 26 & 217.7 & 153.0 & 103.9 & 182.6 & 153.1 & 200.4 & 236.9 & 138.9 & 143.7 & 81.3 & 109.8 & 0.0 \\
\hline & 27 & 124.7 & 80.0 & 133.2 & 88.8 & 88.8 & 106.8 & 186.4 & 55.6 & 68.7 & 96.1 & 91.0 & 76.0 \\
\hline & 28 & 180.3 & 160.7 & 134.0 & 110.5 & 76.3 & 80.0 & 95.6 & 102.6 & 107.6 & 99.7 & 65.7 & 80.1 \\
\hline & 29 & 263.5 & 139.2 & 136.6 & 0.0 & 86.8 & 131.2 & 184.0 & 88.8 & 155.7 & 156.6 & 79.2 & 71.9 \\
\hline & 30 & 93.9 & 59.2 & 59.1 & 52.8 & 65.6 & 75.0 & 99.1 & 58.1 & 62.4 & 66.7 & 66.8 & 46.2 \\
\hline & Average & 215.0 & 127.1 & 134.9 & 72.4 & 78.4 & 98.9 & 133.7 & 74.0 & 89.7 & 83.4 & 68.7 & 45.7 \\
\hline & SE & 46.3 & 18.9 & 24.7 & 28.7 & 20.1 & 27.2 & 34.9 & 19.4 & 23.7 & 20.8 & 15.3 & 15.2 \\
\hline
\end{tabular}

Table Ib. Student's t-test (vs. vehicle), $p<0.05$.

\begin{tabular}{lcccccccccccc}
\hline T-TEST vs. Vehicle & \multicolumn{10}{c}{ Days } \\
\cline { 2 - 13 } & 3 & 5 & 7 & 8 & 10 & 12 & 14 & 15 & 18 & 21 & 24 & 26 \\
\hline DTX $(1 \mathrm{mg} / \mathrm{kg})$ & 0.998 & 0.440 & 0.628 & 0.255 & 0.223 & 0.160 & 0.133 & 0.078 & 0.154 & 0.179 & 0.274 & 0.188 \\
DTX $(2.5 \mathrm{mg} / \mathrm{kg})$ & 0.274 & 0.815 & 0.841 & 0.707 & 0.706 & 0.946 & 0.917 & 0.565 & 0.785 & 0.984 & 0.956 & 0.698 \\
DTX $(5 \mathrm{mg} / \mathrm{kg})$ & 0.460 & 0.419 & 0.756 & 0.640 & 0.454 & 0.299 & 0.349 & 0.183 & 0.270 & 0.243 & 0.175 & 0.352 \\
DTX $(10 \mathrm{mg} / \mathrm{kg})$ & 0.612 & 0.107 & 0.114 & 0.032 & 0.037 & 0.061 & 0.068 & 0.018 & 0.068 & 0.058 & 0.041 & 0.045 \\
\hline
\end{tabular}

almost dose-dependently, except with the administration of $2.5 \mathrm{mg}$ of DTX; significance was observed in the $10 \mathrm{mg} / \mathrm{kg}$ group compared with control.
Next, the inhibitory activities of tumor growth with DTX in xenograft mice after implantation of solid DU145 tumor was examined (Figure 2B). Vehicle or DTX at a wide range 
Table IIa. Relative tumor size (Day 3=100), averaged tumor size and standard error (SE) values.

\begin{tabular}{|c|c|c|c|c|c|c|c|c|c|c|c|c|c|}
\hline \multirow[t]{2}{*}{ Dosage } & \multirow[t]{2}{*}{ Animal No. } & \multicolumn{12}{|c|}{ Days } \\
\hline & & 3 & 5 & 7 & 8 & 10 & 12 & 14 & 15 & 18 & 21 & 24 & 26 \\
\hline \multirow[t]{8}{*}{ Vehicle } & 1 & 100 & 373 & 654 & 856 & 844 & 664 & 924 & 772 & 936 & 1383 & 1676 & 1514 \\
\hline & 2 & 100 & 197 & 166 & 193 & 256 & 366 & 374 & 413 & 335 & 366 & 308 & 322 \\
\hline & 3 & 100 & 94 & 173 & 212 & 222 & 303 & 302 & 407 & 657 & 657 & 564 & 689 \\
\hline & 4 & 100 & 197 & 123 & 111 & 97 & 0 & 0 & 202 & 152 & 64 & 91 & 119 \\
\hline & 5 & 100 & 165 & 195 & 210 & 229 & 249 & 247 & 241 & 272 & 316 & 292 & 350 \\
\hline & 6 & 100 & 50 & 43 & 48 & 32 & 74 & 83 & 85 & 63 & 58 & 42 & 46 \\
\hline & Average & 100 & 179 & 226 & 272 & 280 & 276 & 322 & 353 & 403 & 474 & 496 & 507 \\
\hline & SE & & 46 & 88 & 120 & 118 & 96 & 133 & 98 & 135 & 203 & 248 & 221 \\
\hline DTX & 7 & 100 & 88 & 120 & 54 & 0 & 0 & 0 & 0 & 0 & 0 & 0 & 0 \\
\hline \multirow[t]{7}{*}{$1 \mathrm{mg} / \mathrm{kg}$} & 8 & 100 & 64 & 127 & 93 & 97 & 97 & 100 & 101 & 117 & 173 & 177 & 191 \\
\hline & 9 & 100 & 174 & 210 & 168 & 241 & 105 & 133 & 102 & 134 & 103 & 166 & 0 \\
\hline & 10 & 100 & 108 & 136 & 125 & 122 & 180 & 174 & 229 & 238 & 309 & 421 & 381 \\
\hline & 11 & 100 & 149 & 191 & 178 & 151 & 160 & 153 & 174 & 191 & 220 & 274 & 261 \\
\hline & 12 & 100 & 94 & 61 & 86 & 51 & 43 & 60 & 0 & 0 & 0 & 0 & 0 \\
\hline & Average & 100 & 113 & 141 & 117 & 110 & 97 & 103 & 101 & 113 & 134 & 173 & 139 \\
\hline & SE & & 17 & 22 & 20 & 34 & 28 & 26 & 37 & 40 & 50 & 66 & 67 \\
\hline DTX & 13 & 100 & 89 & 76 & 94 & 106 & 143 & 118 & 126 & 154 & 225 & 165 & 221 \\
\hline \multirow[t]{7}{*}{$2.5 \mathrm{mg} / \mathrm{kg}$} & 14 & 100 & 84 & 141 & 166 & 139 & 146 & 148 & 160 & 244 & 276 & 248 & 451 \\
\hline & 15 & 100 & 124 & 145 & 121 & 118 & 201 & 234 & 200 & 312 & 310 & 319 & 424 \\
\hline & 16 & 100 & 124 & 200 & 241 & 275 & 372 & 368 & 427 & 511 & 646 & 586 & 756 \\
\hline & 17 & 100 & 115 & 60 & 67 & 53 & 43 & 106 & 52 & 16 & 24 & 41 & 21 \\
\hline & 18 & 100 & 79 & 98 & 77 & 103 & 127 & 122 & 92 & 163 & 197 & 191 & 288 \\
\hline & Average & 100 & 103 & 120 & 128 & 132 & 172 & 183 & 176 & 233 & 280 & 258 & 360 \\
\hline & $\mathrm{SE}$ & & 8 & 21 & 27 & 31 & 45 & 42 & 54 & 69 & 84 & 76 & 101 \\
\hline DTX & 19 & 100 & 138 & 99 & 102 & 127 & 131 & 128 & 108 & 126 & 125 & 136 & 180 \\
\hline \multirow[t]{7}{*}{$5 \mathrm{mg} / \mathrm{kg}$} & 20 & 100 & 97 & 285 & 510 & 413 & 365 & 352 & 533 & 746 & 727 & 543 & 1043 \\
\hline & 21 & 100 & 81 & 100 & 86 & 46 & 46 & 86 & 42 & 16 & 44 & 30 & 47 \\
\hline & 22 & 100 & 129 & 185 & 193 & 182 & 186 & 185 & 173 & 202 & 215 & 172 & 245 \\
\hline & 23 & 100 & 40 & 75 & 31 & 41 & 28 & 67 & 75 & 27 & 22 & 35 & 51 \\
\hline & 24 & 100 & 0 & 55 & 54 & 83 & 39 & 83 & 49 & 56 & 33 & 43 & 0 \\
\hline & Average & 100 & 81 & 133 & 163 & 149 & 133 & 150 & 163 & 196 & 194 & 160 & 261 \\
\hline & $\mathrm{SE}$ & & 22 & 35 & 73 & 57 & 53 & 44 & 77 & 114 & 111 & 80 & 161 \\
\hline DTX & 25 & 100 & 42 & 59 & 0 & 0 & 0 & 0 & 0 & 0 & 0 & 0 & 0 \\
\hline \multirow[t]{7}{*}{$10 \mathrm{mg} / \mathrm{kg}$} & 26 & 100 & 70 & 48 & 84 & 70 & 92 & 109 & 64 & 66 & 37 & 50 & 0 \\
\hline & 27 & 100 & 64 & 107 & 71 & 71 & 86 & 150 & 45 & 55 & 77 & 73 & 61 \\
\hline & 28 & 100 & 89 & 74 & 61 & 42 & 44 & 53 & 57 & 60 & 55 & 36 & 44 \\
\hline & 29 & 100 & 53 & 52 & 0 & 33 & 50 & 70 & 34 & 59 & 59 & 30 & 27 \\
\hline & 30 & 100 & 63 & 63 & 56 & 70 & 80 & 106 & 62 & 66 & 71 & 71 & 49 \\
\hline & Average & 100 & 64 & 67 & 45 & 48 & 59 & 81 & 43 & 51 & 50 & 44 & 30 \\
\hline & SE & & 7 & 9 & 15 & 12 & 14 & 21 & 10 & 10 & 11 & 11 & 11 \\
\hline
\end{tabular}

Table IIb. Student's t-test (vs. vehicle), $p<0.05$.

\begin{tabular}{|c|c|c|c|c|c|c|c|c|c|c|c|c|}
\hline \multirow[t]{2}{*}{ T-TEST vs. Vehicle } & \multicolumn{12}{|c|}{ Days } \\
\hline & 3 & 5 & 7 & 8 & 10 & 12 & 14 & 15 & 18 & 21 & 24 & 26 \\
\hline DTX (1 mg/kg) & - & 0.201 & 0.372 & 0.233 & 0.198 & 0.104 & 0.138 & 0.037 & 0.068 & 0.136 & 0.237 & 0.143 \\
\hline DTX $(2.5 \mathrm{mg} / \mathrm{kg})$ & - & 0.129 & 0.272 & 0.268 & 0.254 & 0.351 & 0.342 & 0.146 & 0.291 & 0.397 & 0.381 & 0.561 \\
\hline DTX (5 mg/kg) & - & 0.079 & 0.355 & 0.455 & 0.341 & 0.221 & 0.249 & 0.158 & 0.269 & 0.255 & 0.226 & 0.390 \\
\hline DTX (10 mg/kg) & - & 0.031 & 0.104 & 0.090 & 0.079 & 0.049 & 0.105 & 0.011 & 0.027 & 0.064 & 0.098 & 0.057 \\
\hline
\end{tabular}

of doses $(0.1,0.5,0.75,1,2.5,5$ and $10 \mathrm{mg} / \mathrm{kg})$ were subcutaneously administered once a week for 32 days and the tumor volume and body weights were measured (Figure 4;
Tables IV, V and VI). Tumor sizes were reduced by subcutaneous administration of DTX at 5.0 and $10 \mathrm{mg} / \mathrm{kg}$, while those at $0.1,0.5,0.75,1.0$ and $2.5 \mathrm{mg} / \mathrm{kg}$ did not have 
Table IIIa. Body weights ( $g$ ) and standard error (SE) values.

\begin{tabular}{|c|c|c|c|c|c|c|c|c|c|c|c|c|c|}
\hline \multirow[t]{2}{*}{ Dosage } & \multirow[t]{2}{*}{ Animal No. } & \multicolumn{12}{|c|}{ Days } \\
\hline & & 3 & 5 & 7 & 8 & 10 & 12 & 14 & 15 & 18 & 21 & 24 & 26 \\
\hline \multirow[t]{8}{*}{ Vehicle } & 1 & 15.9 & 20.7 & 22.0 & 21.6 & 22.6 & 22.2 & 22.6 & 22.7 & 22.8 & 23.4 & 23.8 & 23.9 \\
\hline & 2 & 18.0 & 20.1 & 21.6 & 21.2 & 21.9 & 21.7 & 21.7 & 21.4 & 21.2 & 20.6 & 21.8 & 21.2 \\
\hline & 3 & 17.7 & 20.3 & 22.4 & 22.5 & 23.1 & 23.4 & 24.0 & 23.4 & 24.7 & 24.7 & 26.1 & 26.0 \\
\hline & 4 & 19.9 & 21.3 & 23.4 & 22.6 & 23.2 & 22.8 & 23.0 & 22.9 & 22.2 & 22.6 & 23.3 & 23.2 \\
\hline & 5 & 21.0 & 21.8 & 22.6 & 22.0 & 22.5 & 21.6 & 22.2 & 21.8 & 22.3 & 22.6 & 23.0 & 24.0 \\
\hline & 6 & 18.2 & 19.2 & 20.6 & 20.4 & 21.2 & 20.4 & 20.1 & 20.5 & 20.3 & 20.3 & 21.6 & 21.6 \\
\hline & Average & 18.5 & 20.6 & 22.1 & 21.7 & 22.4 & 22.0 & 22.3 & 22.1 & 22.3 & 22.4 & 23.3 & 23.3 \\
\hline & $\mathrm{SE}$ & 0.7 & 0.4 & 0.4 & 0.3 & 0.3 & 0.4 & 0.5 & 0.4 & 0.6 & 0.7 & 0.7 & 0.7 \\
\hline DTX & 7 & 16.4 & 18.5 & 19.2 & 20.2 & 20.9 & 20.8 & 21.2 & 21.2 & 21.2 & 21.3 & 21.8 & 22.0 \\
\hline \multirow{7}{*}{$1 \mathrm{mg} / \mathrm{kg}$} & 8 & 17.6 & 19.4 & 21.0 & 21.6 & 22.1 & 22.2 & 22.2 & 21.9 & 21.2 & 21.9 & 22.2 & 22.6 \\
\hline & 9 & 18.6 & 20.8 & 22.6 & 22.8 & 23.4 & 22.8 & 22.6 & 23.3 & 23.2 & 23.6 & 23.5 & 22.0 \\
\hline & 10 & 19.6 & 21.1 & 21.0 & 21.0 & 21.5 & 21.2 & 21.5 & 22.2 & 22.2 & 22.3 & 22.3 & 23.0 \\
\hline & 11 & 19.8 & 22.3 & 23.4 & 23.8 & 24.3 & 23.8 & 23.6 & 24.4 & 24.0 & 24.5 & 25.2 & 25.2 \\
\hline & 12 & 16.8 & 18.0 & 19.2 & 19.2 & 19.7 & 19.4 & 19.4 & 19.8 & 19.4 & 20.5 & 21.0 & 20.9 \\
\hline & Average & 18.1 & 20.0 & 21.1 & 21.4 & 22.0 & 21.7 & 21.8 & 22.1 & 21.9 & 22.4 & 22.7 & 22.6 \\
\hline & SE & 0.6 & 0.7 & 0.7 & 0.7 & 0.7 & 0.6 & 0.6 & 0.7 & 0.7 & 0.6 & 0.6 & 0.6 \\
\hline DTX & 13 & 16.5 & 18.6 & 20.0 & 19.4 & 19.7 & 18.8 & 19.4 & 19.6 & 19.4 & 20.0 & 19.5 & 20.4 \\
\hline \multirow[t]{7}{*}{$2.5 \mathrm{mg} / \mathrm{kg}$} & 14 & 18.0 & 19.1 & 21.2 & 20.4 & 21.0 & 21.0 & 21.8 & 21.8 & 22.0 & 22.0 & 22.4 & 22.9 \\
\hline & 15 & 17.9 & 20.1 & 22.2 & 21.6 & 22.3 & 21.8 & 22.4 & 22.6 & 22.2 & 22.3 & 23.0 & 23.4 \\
\hline & 16 & 18.8 & 21.5 & 22.2 & 22.0 & 22.5 & 22.2 & 21.6 & 22.8 & 24.4 & 24.4 & 24.6 & 25.1 \\
\hline & 17 & 19.8 & 22.0 & 23.2 & 23.0 & 23.0 & 23.0 & 22.0 & 22.6 & 22.8 & 23.0 & 24.0 & 23.8 \\
\hline & 18 & 19.3 & 21.0 & 21.4 & 21.4 & 21.2 & 20.4 & 20.2 & 20.6 & 21.2 & 21.3 & 20.9 & 20.9 \\
\hline & Average & 18.4 & 20.4 & 21.7 & 21.3 & 21.6 & 21.2 & 21.2 & 21.7 & 22.0 & 22.2 & 22.4 & 22.8 \\
\hline & SE & 0.5 & 0.6 & 0.4 & 0.5 & 0.5 & 0.6 & 0.5 & 0.5 & 0.7 & 0.6 & 0.8 & 0.7 \\
\hline DTX & 19 & 16.7 & 19.0 & 19.8 & 19.6 & 20.2 & 19.6 & 19.4 & 20.0 & 19.8 & 19.9 & 20.1 & 20.2 \\
\hline \multirow[t]{7}{*}{$5 \mathrm{mg} / \mathrm{kg}$} & 20 & 17.9 & 19.0 & 20.2 & 19.6 & 19.8 & 19.8 & 20.6 & 21.0 & 21.3 & 21.2 & 21.5 & 21.7 \\
\hline & 21 & 18.1 & 20.2 & 21.6 & 21.2 & 21.8 & 21.8 & 22.0 & 22.4 & 22.0 & 21.8 & 22.2 & 22.7 \\
\hline & 22 & 18.3 & 20.6 & 21.2 & 21.0 & 21.4 & 21.2 & 21.8 & 21.4 & 21.4 & 21.6 & 21.9 & 22.1 \\
\hline & 23 & 20.8 & 22.0 & 22.8 & 22.4 & 22.2 & 22.4 & 22.4 & 22.6 & 22.8 & 23.3 & 23.4 & 23.4 \\
\hline & 24 & 19.9 & 21.6 & 22.4 & 21.8 & 22.2 & 22.0 & 22.2 & 22.6 & 23.4 & 23.8 & 23.4 & 23.8 \\
\hline & Average & 18.6 & 20.4 & 21.3 & 20.9 & 21.3 & 21.1 & 21.4 & 21.7 & 21.8 & 21.9 & 22.1 & 22.3 \\
\hline & SE & 0.6 & 0.5 & 0.5 & 0.5 & 0.4 & 0.5 & 0.5 & 0.4 & 0.5 & 0.6 & 0.5 & 0.5 \\
\hline DTX & 25 & 17.3 & 18.6 & 20.0 & 19.4 & 19.0 & 18.6 & 18.6 & 18.8 & 18.4 & 18.8 & 18.4 & 18.4 \\
\hline \multirow[t]{7}{*}{$10 \mathrm{mg} / \mathrm{kg}$} & 26 & 18.2 & 18.8 & 20.2 & 20.2 & 20.4 & 19.6 & 20.0 & 20.4 & 20.4 & 20.7 & 20.8 & 21.4 \\
\hline & 27 & 17.7 & 19.0 & 20.8 & 20.8 & 20.6 & 20.4 & 20.6 & 21.6 & 21.6 & 21.4 & 20.8 & 21.2 \\
\hline & 28 & 19.3 & 20.2 & 20.8 & 20.6 & 20.8 & 19.8 & 20.0 & 20.2 & 20.0 & 20.6 & 19.8 & 20.4 \\
\hline & 29 & 21.6 & 22.4 & 23.4 & 23.0 & 23.0 & 22.8 & 22.6 & 22.6 & 22.8 & 23.0 & 22.6 & 23.0 \\
\hline & 30 & 18.0 & 18.8 & 20.2 & 19.8 & 19.6 & 19.4 & 20.0 & 20.6 & 19.8 & 21.0 & 20.4 & 21.4 \\
\hline & Average & 18.7 & 19.6 & 20.9 & 20.6 & 20.6 & 20.1 & 20.3 & 20.7 & 20.5 & 20.9 & 20.5 & 21.0 \\
\hline & SE & 0.6 & 0.6 & 0.5 & 0.5 & 0.6 & 0.6 & 0.5 & 0.5 & 0.6 & 0.6 & 0.6 & 0.6 \\
\hline
\end{tabular}

Table IIIb. Student's t-test (vs. vehicle).

\begin{tabular}{|c|c|c|c|c|c|c|c|c|c|c|c|c|}
\hline \multirow[t]{2}{*}{ T-TEST $v s$. Vehicle } & \multicolumn{12}{|c|}{ Days } \\
\hline & 3 & 5 & 7 & 8 & 10 & 12 & 14 & 15 & 18 & 21 & 24 & 26 \\
\hline DTX $(1 \mathrm{mg} / \mathrm{kg})$ & - & 0.800 & 0.674 & 0.759 & 0.683 & 0.618 & 0.516 & 0.573 & 0.425 & 0.382 & 0.275 & 0.237 \\
\hline DTX $(2.5 \mathrm{mg} / \mathrm{kg})$ & - & 0.782 & 0.725 & 0.676 & 0.581 & 0.504 & 0.408 & 0.468 & 0.401 & 0.335 & 0.249 & 0.255 \\
\hline DTX $(5 \mathrm{mg} / \mathrm{kg})$ & - & 0.764 & 0.628 & 0.595 & 0.490 & 0.446 & 0.382 & 0.410 & 0.308 & 0.245 & 0.166 & 0.158 \\
\hline DTX $(10 \mathrm{mg} / \mathrm{kg})$ & - & 0.709 & 0.618 & 0.601 & 0.449 & 0.353 & 0.279 & 0.315 & 0.223 & 0.185 & 0.086 & 0.092 \\
\hline
\end{tabular}

an obvious effect on the tumor size (Figure 4A and B). Tumors filled with liquid were also observed in mice in the $2.5 \mathrm{mg} / \mathrm{kg}$ DTX group. Growth suppression of the body weight in the $10 \mathrm{mg} / \mathrm{kg}$ DTX group was also observed (Figure 4C). It is known that clinical use of DTX can cause edema (6); similar phenomena were observed in mice at the 

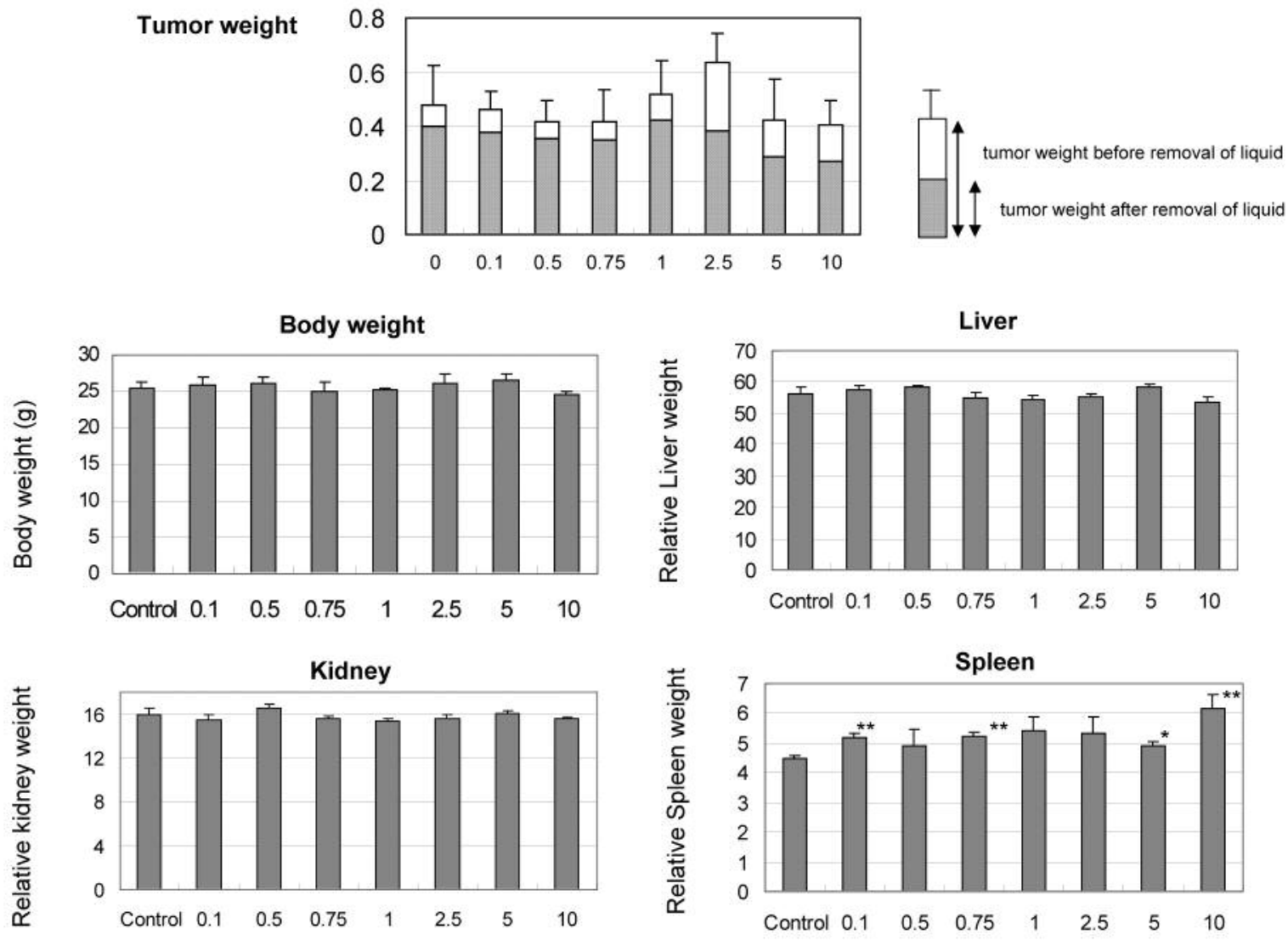

Figure 5. Average of the relative weights of the tumor, body weight, liver, kidneys and spleen. Each value represents the mean \pm SE of five mice. * and $* *$ indicate $p<0.05$ and 0.01 compared to control with Student's $t$-test. Each relative weight was estimated by the following formula: (relative organ weight $)(\mathrm{g} / \mathrm{kg})=($ weight of organs $)(\mathrm{g}) /($ body weight $)(\mathrm{kg})$.

$2.5 \mathrm{mg} / \mathrm{kg}$ dose of DTX (Figure 4D). In that group, almost $40 \%$ of the tumor weight consisted of liquid matter (Figure 5) and significance was observed in the fluid weight of the tumor compared with control. To estimate the toxicity with the administration of DTX, the weights of body, liver, kidneys and spleen were measured on the final day; they were nearly at the control levels (Figure 5). Hypertrophy of the spleen was frequently noted at all conditions, while dose-dependence was unclear. The concentrations of plasma GOT, GPT, creatinine and BUN on the final day were also estimated. GOT and GPT values were significantly low, except for at $0.1 \mathrm{mg} / \mathrm{kg}$ (Figure 6). BUN and creatinine were somewhat increased, albeit not dose-dependently.

\section{Discussion}

Inhibitory activities of DTX in DU145 xenograft mice were examined under two conditions (Figure 2A and B). DTX was subcutaneously injected for 26 days (Figure 3; Tables I, II and III) or 32 days (Figure 4; Tables IV, V and VI), once per week, and the tumor volume and body weights were measured. In previously reported works, administration of 25 $\mathrm{mg} / \mathrm{kg}$ DTX (intravenously (i.v.), 5 days/week, 6 weeks) completely suppressed DU145 tumor growth in a xenograft model (7), while, intraperitoneally (i.p.), at $10 \mathrm{mg} / \mathrm{kg}$ (once/week, 3 weeks), DTX partially inhibited the growth of DU145 tumors in a xenograft model (8). Moreover, there are similar reports at a dose higher than $15 \mathrm{mg} / \mathrm{kg}$ in an interview (Sanofi Co. Ltd.) (5) and over $8.9 \mathrm{mg} / \mathrm{kg}$ elsewhere (9). However, DTX is clinically used at a dose of almost 2$3 \mathrm{mg} / \mathrm{kg}\left(75 \mathrm{mg} / \mathrm{m}^{2}\right)$ by infusion over 3 hours once every 3 weeks in Japan (5). According to our search, this is the first report to examine the dose-dependence of DTX at a wide range of doses on the inhibition of tumor growth in xenograft mice bearing DU145 tumors. DTX at 1,5 and $10 \mathrm{mg} / \mathrm{kg}$ doses inhibited tumor growth in a xenograft model that was developed by the injection of DU145 cells (Figure 3). However, suppression of tumor growth was not observed 
Table IVa. Tumor size $\left(\mathrm{mm}^{3}\right)$, averaged tumor size and standard error (SE) values.

\begin{tabular}{|c|c|c|c|c|c|c|c|c|c|c|c|}
\hline \multirow[t]{2}{*}{ Dosage } & \multirow[t]{2}{*}{ Animal No. } & \multicolumn{10}{|c|}{ Days } \\
\hline & & 1 & 4 & 8 & 11 & 14 & 17 & 21 & 24 & 28 & 32 \\
\hline \multirow[t]{7}{*}{ Vehicle } & 31 & 53.7 & 54.2 & 114.9 & 89.2 & 114.4 & 134.54 & 159.0 & 201.6 & 276.8 & 397.8 \\
\hline & 32 & 62.4 & 122.4 & 143.4 & 198.5 & 230.6 & 235.20 & 277.2 & 290.5 & 399.4 & 548.4 \\
\hline & 33 & 84.7 & 159.5 & 198.5 & 321.5 & 325.1 & 276.82 & 428.1 & 418.2 & 494.0 & 670.7 \\
\hline & 34 & 94.9 & 213.6 & 269.8 & 328.1 & 414.7 & 422.33 & 665.5 & 984.4 & 1201.3 & 1481.1 \\
\hline & 35 & 111.3 & 177.3 & 212.7 & 365.1 & 469.8 & 617.98 & 812.3 & 1149.2 & 1430.7 & 1503.4 \\
\hline & Mean & 81.4 & 145.4 & 187.8 & 260.5 & 310.9 & 337.37 & 468.4 & 608.8 & 760.4 & 920.3 \\
\hline & $\mathrm{SE}$ & 10.5 & 27.1 & 27.2 & 51.2 & 63.8 & 84.03 & 120.6 & 191.9 & 232.2 & 237.5 \\
\hline DTX & 36 & 50.4 & 146.9 & 303.2 & 449.6 & 429.0 & 673.67 & 716.6 & 1027.0 & 930.2 & 1090.4 \\
\hline \multirow[t]{6}{*}{$0.1 \mathrm{mg} / \mathrm{kg}$} & 37 & 66.7 & 126.9 & 132.1 & 233.4 & 306.6 & 367.84 & 447.2 & 532.5 & 652.9 & 670.0 \\
\hline & 38 & 71.4 & 175.7 & 220.3 & 450.6 & 370.9 & 465.75 & 578.7 & 675.5 & 1046.9 & 1211.0 \\
\hline & 39 & 106.0 & 189.6 & 193.0 & 303.4 & 272.3 & 283.97 & 284.8 & 358.7 & 562.3 & 557.0 \\
\hline & 40 & 112.1 & 158.8 & 231.9 & 292.0 & 213.4 & 244.49 & 322.5 & 426.3 & 612.9 & 672.3 \\
\hline & Mean & 81.3 & 159.6 & 216.1 & 345.8 & 318.4 & 407.14 & 469.9 & 604.0 & 761.0 & 840.1 \\
\hline & SE & 11.9 & 10.9 & 27.8 & 44.2 & 37.6 & 76.70 & 80.4 & 118.5 & 95.8 & 129.9 \\
\hline DTX & 41 & 46.6 & 118.6 & 239.7 & 332.8 & 401.2 & 358.40 & 480.3 & 495.1 & 622.4 & 758.2 \\
\hline \multirow{6}{*}{$0.5 \mathrm{mg} / \mathrm{kg}$} & 42 & 57.6 & 75.8 & 95.6 & 81.6 & 97.5 & 111.39 & 173.4 & 171.1 & 279.3 & 382.3 \\
\hline & 43 & 86.0 & 114.9 & 190.8 & 241.9 & 213.6 & 242.59 & 368.3 & 336.0 & 483.8 & 649.0 \\
\hline & 44 & 103.9 & 223.8 & 251.4 & 425.0 & 494.1 & 496.86 & 472.4 & 486.7 & 645.0 & 839.8 \\
\hline & 45 & 117.0 & 171.5 & 379.5 & 418.2 & 446.6 & 763.99 & 1000.8 & 1254.5 & 2107.5 & 1362.1 \\
\hline & Mean & 82.2 & 140.9 & 231.4 & 299.9 & 330.6 & 394.65 & 499.0 & 548.7 & 827.6 & 798.3 \\
\hline & SE & 13.4 & 25.7 & 46.1 & 63.9 & 75.2 & 112.15 & 137.1 & 186.1 & 326.5 & 160.7 \\
\hline DTX & 46 & 44.4 & 50.3 & 127.0 & 123.6 & 139.4 & 152.46 & 168.8 & 213.2 & 287.1 & 202.6 \\
\hline \multirow{6}{*}{$0.75 \mathrm{mg} / \mathrm{kg}$} & 47 & 62.4 & 136.5 & 194.5 & 295.9 & 336.0 & 389.34 & 511.5 & 612.1 & 772.8 & 1089.3 \\
\hline & 48 & 81.1 & 124.5 & 161.4 & 218.1 & 196.5 & 178.18 & 204.7 & 312.1 & 362.4 & 447.2 \\
\hline & 49 & 102.7 & 181.3 & 292.0 & 439.6 & 461.7 & 459.60 & 615.3 & 1086.5 & 1421.6 & 1415.8 \\
\hline & 50 & 117.2 & 181.5 & 262.1 & 329.3 & 313.6 & 340.22 & 443.6 & 488.4 & 640.5 & 717.3 \\
\hline & Mean & 81.6 & 134.8 & 207.4 & 281.3 & 289.4 & 303.96 & 388.8 & 542.5 & 696.9 & 774.4 \\
\hline & $\mathrm{SE}$ & 13.2 & 24.1 & 30.7 & 53.1 & 56.4 & 59.83 & 87.1 & 152.5 & 201.7 & 217.7 \\
\hline DTX & 51 & 45.5 & 101.9 & 170.6 & 245.5 & 233.3 & 340.61 & 303.2 & 414.3 & 348.8 & 404.6 \\
\hline \multirow{6}{*}{$1 \mathrm{mg} / \mathrm{kg}$} & 52 & 57.3 & 102.8 & 222.0 & 426.5 & 481.6 & 545.72 & 590.0 & 646.9 & 792.6 & 837.8 \\
\hline & 53 & 81.6 & 148.1 & 254.9 & 249.4 & 270.7 & 285.91 & 358.7 & 342.2 & 363.4 & 426.5 \\
\hline & 54 & 99.8 & 188.5 & 188.5 & 356.4 & 320.6 & 382.34 & 473.1 & 700.2 & 1118.7 & 1156.6 \\
\hline & 55 & 120.9 & 180.9 & 243.7 & 323.8 & 317.5 & 450.64 & 521.3 & 646.9 & 886.1 & 1166.9 \\
\hline & Mean & 81.0 & 144.4 & 215.9 & 320.3 & 324.7 & 401.04 & 449.3 & 550.1 & 701.9 & 798.5 \\
\hline & SE & 13.7 & 18.5 & 16.0 & 34.1 & 42.4 & 45.08 & 52.5 & 71.7 & 150.9 & 167.2 \\
\hline DTX & 56 & 35.6 & 97.5 & 108.8 & 97.5 & 119.1 & 202.50 & 282.1 & 402.2 & 702.3 & 1067.7 \\
\hline \multirow[t]{6}{*}{$2.5 \mathrm{mg} / \mathrm{kg}$} & 57 & 54.4 & 61.9 & 102.5 & 144.3 & 181.8 & 234.48 & 290.5 & 423.4 & 605.4 & 773.3 \\
\hline & 58 & 76.7 & 82.5 & 181.3 & 181.7 & 262.8 & 293.49 & 422.7 & 494.1 & 612.6 & 769.8 \\
\hline & 59 & 109.8 & 189.2 & 237.1 & 335.2 & 292.8 & 424.13 & 483.8 & 582.6 & 566.2 & 682.3 \\
\hline & 60 & 133.0 & 176.1 & 230.7 & 452.8 & 480.3 & 549.21 & 656.7 & 822.0 & 1021.5 & 1390.6 \\
\hline & Mean & 81.9 & 121.5 & 172.1 & 242.3 & 267.4 & 340.76 & 427.2 & 544.9 & 701.6 & 936.8 \\
\hline & SE & 17.8 & 25.7 & 28.8 & 66.0 & 61.4 & 64.44 & 69.1 & 76.1 & 83.0 & 130.9 \\
\hline DTX & 61 & 31.9 & 32.2 & 77.2 & 85.8 & 106.8 & 121.84 & 151.8 & 223.8 & 384.2 & 467.0 \\
\hline \multirow[t]{6}{*}{$5 \mathrm{mg} / \mathrm{kg}$} & 62 & 61.2 & 66.3 & 56.4 & 27.7 & 66.3 & 73.75 & 64.5 & 111.4 & 76.7 & 65.2 \\
\hline & 63 & 86.0 & 180.3 & 264.7 & 380.7 & 515.2 & 540.65 & 633.9 & 670.6 & 664.0 & 837.8 \\
\hline & 64 & 90.4 & 113.4 & 227.3 & 151.2 & 356.2 & 413.10 & 585.8 & 714.1 & 801.1 & 933.1 \\
\hline & 65 & 141.0 & 226.8 & 326.4 & 386.5 & 482.8 & 434.75 & 475.7 & 476.2 & 580.6 & 576.2 \\
\hline & Mean & 82.1 & 123.8 & 190.4 & 206.4 & 305.5 & 316.82 & 382.4 & 439.2 & 501.3 & 575.9 \\
\hline & SE & 18.0 & 35.8 & 53.0 & 74.9 & 93.4 & 92.30 & 115.7 & 119.2 & 125.8 & 153.1 \\
\hline DTX & 66 & 29.4 & 49.6 & 62.8 & 138.4 & 191.8 & 191.56 & 353.0 & 425.9 & 605.0 & 646.9 \\
\hline \multirow[t]{6}{*}{$10 \mathrm{mg} / \mathrm{kg}$} & 67 & 66.3 & 71.4 & 110.5 & 123.6 & 186.2 & 257.03 & 233.3 & 322.8 & 459.5 & 527.6 \\
\hline & 68 & 70.8 & 119.1 & 211.7 & 234.2 & 210.8 & 236.25 & 305.1 & 307.2 & 298.5 & 358.2 \\
\hline & 69 & 87.1 & 78.4 & 153.8 & 213.2 & 223.0 & 214.25 & 254.8 & 246.2 & 373.5 & 465.5 \\
\hline & 70 & 154.2 & 323.8 & 345.7 & 475.2 & 556.6 & 585.00 & 758.9 & 647.1 & 863.3 & 920.5 \\
\hline & Mean & 81.6 & 128.4 & 176.9 & 236.9 & 273.7 & 296.82 & 381.0 & 389.9 & 520.0 & 583.7 \\
\hline & SE & 20.5 & 50.1 & 48.8 & 63.2 & 71.0 & 72.87 & 96.7 & 70.5 & 99.8 & 96.3 \\
\hline
\end{tabular}

Table IVb. Student's t-test (vs. vehicle).

T-TEST $v s$. Vehicle

Days

\begin{tabular}{lccccccccrc} 
& \multicolumn{1}{c}{1} & 4 & 8 & 11 & 14 & 17 & 21 & 24 & 28 & 32 \\
\hline DTX $(0.1 \mathrm{mg} / \mathrm{lg})$ & 0.995 & 0.641 & 0.487 & 0.243 & 0.922 & 0.557 & 0.992 & 0.984 & 0.998 & 0.775 \\
DTX $(0.5 \mathrm{mg} / \mathrm{kg})$ & 0.963 & 0.908 & 0.439 & 0.643 & 0.847 & 0.693 & 0.871 & 0.828 & 0.871 & 0.682 \\
DTX $(0.75 \mathrm{mg} / \mathrm{kg})$ & 0.993 & 0.778 & 0.646 & 0.785 & 0.807 & 0.754 & 0.607 & 0.794 & 0.841 & 0.663 \\
DTX $(1 \mathrm{mg} / \mathrm{kg})$ & 0.984 & 0.977 & 0.399 & 0.359 & 0.861 & 0.523 & 0.888 & 0.782 & 0.838 & 0.686 \\
DTX $(2.5 \mathrm{mg} / \mathrm{kg})$ & 0.982 & 0.539 & 0.701 & 0.833 & 0.636 & 0.975 & 0.774 & 0.765 & 0.817 & 0.953 \\
DTX $(5 \mathrm{mg} / \mathrm{kg})$ & 0.975 & 0.644 & 0.967 & 0.568 & 0.963 & 0.873 & 0.621 & 0.474 & 0.355 & 0.258 \\
DTX $(10 \mathrm{mg} / \mathrm{kg})$ & 0.995 & 0.774 & 0.850 & 0.779 & 0.707 & 0.725 & 0.587 & 0.315 & 0.369 & 0.226 \\
\hline
\end{tabular}


Table Va. Relative tumor size (day 1=100), averaged tumor size and standard error (SE) values.

\begin{tabular}{|c|c|c|c|c|c|c|c|c|c|c|c|}
\hline \multirow[t]{2}{*}{ Dosage } & \multirow[t]{2}{*}{ Animal No. } & \multicolumn{10}{|c|}{ Days } \\
\hline & & 1 & 4 & 8 & 11 & 14 & 17 & 21 & 24 & 28 & 32 \\
\hline \multirow[t]{7}{*}{ Vehicle } & 31 & 100 & 101 & 214 & 166 & 213 & 251 & 296 & 376 & 516 & 741 \\
\hline & 32 & 100 & 196 & 230 & 318 & 369 & 377 & 444 & 465 & 640 & 878 \\
\hline & 33 & 100 & 188 & 234 & 380 & 384 & 327 & 505 & 494 & 583 & 792 \\
\hline & 34 & 100 & 225 & 284 & 346 & 437 & 445 & 701 & 1037 & 1265 & 1560 \\
\hline & 35 & 100 & 159 & 191 & 328 & 422 & 555 & 730 & 1032 & 1285 & 1350 \\
\hline & Mean & 100 & 174 & 231 & 307 & 365 & 391 & 535 & 681 & 858 & 1064 \\
\hline & SE & & 21 & 15 & 37 & 40 & 52 & 81 & 146 & 172 & 164 \\
\hline DTX & 36 & 100 & 291 & 601 & 891 & 851 & 1336 & 1421 & 2036 & 1845 & 2162 \\
\hline \multirow[t]{6}{*}{$0.1 \mathrm{mg} / \mathrm{kg}$} & 37 & 100 & 190 & 198 & 350 & 460 & 552 & 671 & 799 & 979 & 1005 \\
\hline & 38 & 100 & 246 & 308 & 631 & 519 & 652 & 810 & 946 & 1466 & 1695 \\
\hline & 39 & 100 & 179 & 182 & 286 & 257 & 268 & 269 & 339 & 531 & 526 \\
\hline & 40 & 100 & 142 & 207 & 261 & 190 & 218 & 288 & 380 & 547 & 600 \\
\hline & Mean & 100 & 210 & 299 & 484 & 455 & 605 & 692 & 900 & 1073 & 1198 \\
\hline & SE & & 26 & 79 & 121 & 116 & 200 & 211 & 307 & 258 & 318 \\
\hline DTX & 41 & 100 & 255 & 515 & 715 & 861 & 770 & 1031 & 1063 & 1336 & 1628 \\
\hline \multirow[t]{6}{*}{$0.5 \mathrm{mg} / \mathrm{kg}$} & 42 & 100 & 132 & 166 & 142 & 169 & 193 & 301 & 297 & 485 & 664 \\
\hline & 43 & 100 & 134 & 222 & 281 & 248 & 282 & 428 & 391 & 562 & 754 \\
\hline & 44 & 100 & 215 & 242 & 409 & 475 & 478 & 455 & 468 & 621 & 808 \\
\hline & 45 & 100 & 147 & 324 & 357 & 382 & 653 & 855 & 1072 & 1801 & 1164 \\
\hline & Mean & 100 & 176 & 294 & 381 & 427 & 475 & 614 & 658 & 961 & 1004 \\
\hline & SE & & 25 & 61 & 95 & 121 & 108 & 140 & 169 & 260 & 178 \\
\hline DTX & 46 & 100 & 113 & 286 & 278 & 314 & 344 & 380 & 480 & 647 & 456 \\
\hline \multirow[t]{6}{*}{$0.75 \mathrm{mg} / \mathrm{kg}$} & 47 & 100 & 219 & 312 & 474 & 538 & 624 & 819 & 981 & 1238 & 1745 \\
\hline & 48 & 100 & 153 & 199 & 269 & 242 & 220 & 252 & 385 & 447 & 551 \\
\hline & 49 & 100 & 177 & 284 & 428 & 450 & 448 & 599 & 1058 & 1384 & 1379 \\
\hline & 50 & 100 & 155 & 224 & 281 & 268 & 290 & 378 & 417 & 546 & 612 \\
\hline & Mean & 100 & 163 & 261 & 346 & 362 & 385 & 486 & 664 & 852 & 949 \\
\hline & SE & & 17 & 21 & 44 & 57 & 70 & 100 & 146 & 191 & 258 \\
\hline DTX & 51 & 100 & 224 & 375 & 540 & 513 & 749 & 667 & 911 & 767 & 889 \\
\hline \multirow[t]{6}{*}{$1 \mathrm{mg} / \mathrm{kg}$} & 52 & 100 & 179 & 387 & 744 & 840 & 952 & 1029 & 1129 & 1383 & 1462 \\
\hline & 53 & 100 & 181 & 312 & 306 & 332 & 350 & 439 & 419 & 445 & 522 \\
\hline & 54 & 100 & 189 & 189 & 357 & 321 & 383 & 474 & 701 & 1121 & 1159 \\
\hline & 55 & 100 & 150 & 202 & 268 & 263 & 373 & 431 & 535 & 733 & 965 \\
\hline & Mean & 100 & 185 & 293 & 443 & 454 & 561 & 608 & 739 & 890 & 999 \\
\hline & SE & & 12 & 42 & 89 & 105 & 122 & 114 & 128 & 163 & 155 \\
\hline DTX & 56 & 100 & 273 & 305 & 273 & 334 & 568 & 792 & 1128 & 1970 & 2996 \\
\hline \multirow[t]{6}{*}{$2.5 \mathrm{mg} / \mathrm{kg}$} & 57 & 100 & 114 & 188 & 265 & 334 & 431 & 534 & 778 & 1113 & 1422 \\
\hline & 58 & 100 & 108 & 236 & 237 & 343 & 382 & 551 & 644 & 798 & 1003 \\
\hline & 59 & 100 & 172 & 216 & 305 & 267 & 386 & 441 & 531 & 516 & 622 \\
\hline & 60 & 100 & 132 & 173 & 341 & 361 & 413 & 494 & 618 & 768 & 1046 \\
\hline & Mean & 100 & 160 & 224 & 284 & 328 & 436 & 562 & 740 & 1033 & 1418 \\
\hline & SE & & 31 & 23 & 18 & 16 & 34 & 60 & 105 & 253 & 414 \\
\hline DTX & 61 & 100 & 101 & 242 & 269 & 335 & 383 & 477 & 703 & 1206 & 1466 \\
\hline \multirow[t]{6}{*}{$5 \mathrm{mg} / \mathrm{kg}$} & 62 & 100 & 108 & 92 & 45 & 108 & 120 & 105 & 182 & 125 & 106 \\
\hline & 63 & 100 & 210 & 308 & 443 & 599 & 629 & 737 & 780 & 772 & 974 \\
\hline & 64 & 100 & 125 & 251 & 167 & 394 & 457 & 648 & 790 & 886 & 1032 \\
\hline & 65 & 100 & 161 & 232 & 274 & 342 & 308 & 337 & 338 & 412 & 409 \\
\hline & Mean & 100 & 141 & 225 & 240 & 356 & 379 & 461 & 558 & 680 & 798 \\
\hline & SE & & 20 & 36 & 66 & 78 & 84 & 113 & 125 & 188 & 241 \\
\hline DTX & 66 & 100 & 168 & 213 & 470 & 652 & 651 & 1199 & 1447 & 2055 & 2198 \\
\hline \multirow[t]{6}{*}{$10 \mathrm{mg} / \mathrm{kg}$} & 67 & 100 & 101 & 156 & 174 & 263 & 363 & 329 & 456 & 649 & 745 \\
\hline & 68 & 100 & 168 & 299 & 331 & 298 & 334 & 431 & 434 & 421 & 506 \\
\hline & 69 & 100 & 90 & 176 & 245 & 256 & 246 & 292 & 283 & 429 & 534 \\
\hline & 70 & 100 & 210 & 224 & 308 & 361 & 379 & 492 & 420 & 560 & 597 \\
\hline & Mean & 100 & 147 & 214 & 306 & 366 & 394 & 549 & 608 & 823 & 916 \\
\hline & SE & & 23 & 25 & 49 & 74 & 68 & 166 & 212 & 311 & 323 \\
\hline
\end{tabular}

Table Vb. Student's t-test (vs. vehicle).

T-TEST $v$. Vehicle

Days

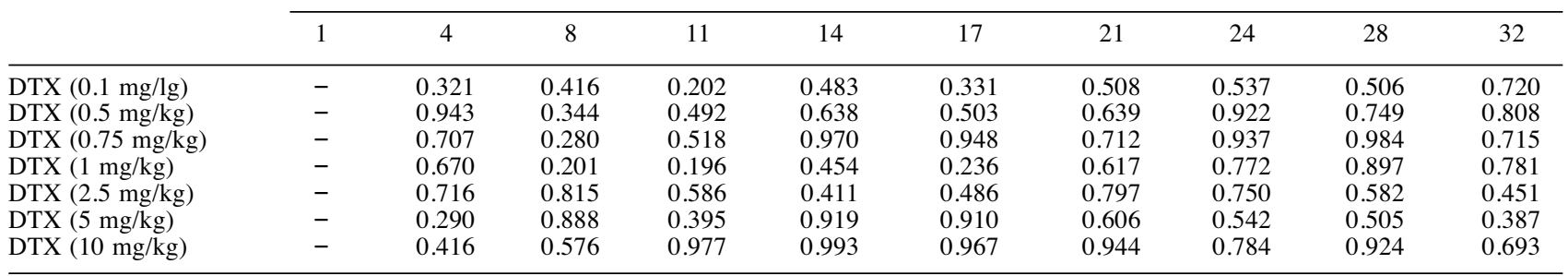


Table VIa. Body weights $(g)$ and standard error (SE) values.

\begin{tabular}{|c|c|c|c|c|c|c|c|c|c|c|c|c|}
\hline \multirow[t]{2}{*}{ Dosage } & \multirow[t]{2}{*}{ Animal No. } & \multicolumn{11}{|c|}{ Days } \\
\hline & & 1 & 4 & 8 & 11 & 14 & 17 & 21 & 24 & 28 & 32 & 33 \\
\hline \multirow{7}{*}{ Vehicle } & 31 & 23.4 & 23.3 & 23.6 & 24.2 & 24.7 & 25.1 & 25.6 & 25.4 & 26.0 & 26.1 & 26.4 \\
\hline & 32 & 24.5 & 24.3 & 24.0 & 24.4 & 24.4 & 25.4 & 25.6 & 25.7 & 26.5 & 26.6 & 27.0 \\
\hline & 33 & 23.6 & 23.9 & 23.9 & 24.0 & 24.0 & 24.4 & 25.9 & 25.6 & 26.0 & 26.0 & 26.1 \\
\hline & 34 & 23.8 & 23.7 & 24.8 & 25.1 & 24.5 & 24.6 & 25.0 & 25.0 & 25.6 & 25.8 & 25.7 \\
\hline & 35 & 23.0 & 23.2 & 23.6 & 24.1 & 24.0 & 24.3 & 23.6 & 23.2 & 22.5 & 21.6 & 22.0 \\
\hline & Mean & 23.7 & 23.7 & 24.0 & 24.4 & 24.3 & 24.8 & 25.1 & 25.0 & 25.3 & 25.2 & 25.4 \\
\hline & SE & 0.2 & 0.2 & 0.2 & 0.2 & 0.1 & 0.2 & 0.4 & 0.5 & 0.7 & 0.9 & 0.9 \\
\hline DTX & 36 & 23.0 & 23.8 & 23.8 & 24.5 & 23.8 & 24.6 & 25.0 & 25.0 & 25.5 & 26.0 & 25.7 \\
\hline \multirow[t]{6}{*}{$0.1 \mathrm{mg} / \mathrm{kg}$} & 37 & 25.7 & 25.4 & 26.4 & 26.5 & 26.6 & 26.6 & 27.0 & 27.0 & 27.9 & 27.6 & 27.7 \\
\hline & 38 & 26.0 & 25.8 & 26.1 & 27.0 & 26.2 & 26.7 & 27.0 & 26.8 & 27.4 & 27.6 & 28.1 \\
\hline & 39 & 22.8 & 23.1 & 22.8 & 23.3 & 23.0 & 23.5 & 23.6 & 23.8 & 24.6 & 24.8 & 25.3 \\
\hline & 40 & 21.4 & 21.3 & 21.4 & 22.1 & 22.2 & 22.4 & 22.4 & 22.2 & 22.9 & 22.6 & 22.4 \\
\hline & Mean & 23.8 & 23.9 & 24.1 & 24.7 & 24.4 & 24.8 & 25.0 & 25.0 & 25.7 & 25.7 & 25.8 \\
\hline & SE & 0.9 & 0.8 & 1.0 & 0.9 & 0.9 & 0.8 & 0.9 & 0.9 & 0.9 & 0.9 & 1.0 \\
\hline DTX & 41 & 22.7 & 22.9 & 23.3 & 22.9 & 23.4 & 23.2 & 23.2 & 22.6 & 23.8 & 23.8 & 24.5 \\
\hline \multirow[t]{6}{*}{$0.5 \mathrm{mg} / \mathrm{kg}$} & 42 & 24.0 & 24.2 & 23.8 & 24.6 & 24.8 & 25.8 & 25.8 & 26.2 & 26.9 & 26.8 & 27.0 \\
\hline & 43 & 22.2 & 22.1 & 22.5 & 22.5 & 22.8 & 23.4 & 23.8 & 23.4 & 23.9 & 24.2 & 24.2 \\
\hline & 44 & 25.6 & 25.3 & 25.0 & 26.1 & 25.0 & 26.6 & 27.0 & 26.4 & 26.7 & 27.4 & 27.3 \\
\hline & 45 & 24.8 & 24.3 & 24.8 & 25.5 & 26.0 & 26.6 & 27.0 & 26.4 & 27.6 & 27.2 & 27.7 \\
\hline & Mean & 23.9 & 23.8 & 23.9 & 24.3 & 24.4 & 25.1 & 25.4 & 25.0 & 25.8 & 25.9 & 26.1 \\
\hline & $\mathrm{SE}$ & 0.6 & 0.6 & 0.5 & 0.7 & 0.6 & 0.8 & 0.8 & 0.8 & 0.8 & 0.8 & 0.7 \\
\hline DTX & 46 & 23.0 & 22.6 & 22.9 & 23.4 & 23.2 & 24.0 & 24.4 & 23.6 & 23.6 & 23.4 & 23.3 \\
\hline \multirow{6}{*}{$0.75 \mathrm{mg} / \mathrm{kg}$} & 47 & 26.0 & 26.2 & 26.1 & 26.3 & 27.0 & 27.6 & 28.2 & 27.6 & 28.5 & 29.2 & 29.4 \\
\hline & 48 & 22.4 & 22.9 & 23.5 & 24.3 & 24.2 & 24.2 & 24.2 & 23.8 & 25.1 & 25.4 & 25.7 \\
\hline & 49 & 23.0 & 23.0 & 22.6 & 23.3 & 23.2 & 23.0 & 23.2 & 23.4 & 24.1 & 24.4 & 24.5 \\
\hline & 50 & 20.9 & 21.0 & 20.4 & 21.7 & 21.2 & 21.6 & 21.8 & 21.4 & 21.9 & 21.8 & 22.1 \\
\hline & Mean & 23.1 & 23.1 & 23.1 & 23.8 & 23.8 & 24.1 & 24.4 & 24.0 & 24.6 & 24.8 & 25.0 \\
\hline & SE & 0.8 & 0.8 & 0.9 & 0.8 & 0.9 & 1.0 & 1.1 & 1.0 & 1.1 & 1.2 & 1.3 \\
\hline DTX & 51 & 24.4 & 23.9 & 23.3 & 24.1 & 23.8 & 24.8 & 24.6 & 24.6 & 24.6 & 24.6 & 24.4 \\
\hline \multirow[t]{6}{*}{$1 \mathrm{mg} / \mathrm{kg}$} & 52 & 23.3 & 23.0 & 23.4 & 23.9 & 23.8 & 23.8 & 24.4 & 24.4 & 24.6 & 24.2 & 24.7 \\
\hline & 53 & 22.0 & 22.2 & 22.0 & 22.4 & 23.4 & 23.8 & 23.8 & 24.0 & 24.4 & 24.4 & 24.5 \\
\hline & 54 & 23.6 & 23.6 & 24.0 & 24.4 & 24.8 & 25.4 & 25.8 & 25.2 & 25.8 & 25.6 & 26.2 \\
\hline & 55 & 22.6 & 23.1 & 22.9 & 24.0 & 24.0 & 24.6 & 24.8 & 24.4 & 25.1 & 26.0 & 25.8 \\
\hline & Mean & 23.2 & 23.2 & 23.1 & 24.8 & 24.0 & 24.5 & 24.7 & 24.5 & 24.9 & 25.0 & 25.1 \\
\hline & SE & 0.4 & 0.3 & 0.3 & 1.2 & 0.2 & 0.3 & 0.3 & 0.2 & 0.3 & 0.4 & 0.4 \\
\hline DTX & 56 & 23.8 & 24.1 & 24.1 & 24.3 & 25.2 & 25.0 & 24.6 & 25.0 & 26.6 & 27.2 & 27.3 \\
\hline \multirow[t]{6}{*}{$2.5 \mathrm{mg} / \mathrm{kg}$} & 57 & 21.1 & 21.6 & 21.7 & 21.9 & 22.0 & 21.8 & 21.8 & 22.2 & 23.0 & 23.2 & 23.4 \\
\hline & 58 & 21.8 & 21.4 & 21.7 & 22.1 & 22.8 & 22.6 & 22.8 & 23.0 & 23.6 & 23.8 & 23.8 \\
\hline & 59 & 22.9 & 23.4 & 23.2 & 23.8 & 23.8 & 24.2 & 24.6 & 25.2 & 25.4 & 25.2 & 25.6 \\
\hline & 60 & 27.0 & 27.5 & 27.4 & 28.5 & 28.0 & 28.4 & 28.8 & 29.0 & 30.0 & 30.2 & 30.7 \\
\hline & Mean & 23.3 & 23.6 & 23.6 & 24.1 & 24.4 & 24.4 & 24.5 & 24.9 & 25.7 & 25.9 & 26.2 \\
\hline & SE & 1.0 & 1.1 & 1.1 & 1.2 & 1.1 & 1.1 & 1.2 & 1.2 & 1.2 & 1.3 & 1.3 \\
\hline DTX & 61 & 23.2 & 22.2 & 22.3 & 21.7 & 22.0 & 22.2 & 23.4 & 23.0 & 23.4 & 23.4 & 23.9 \\
\hline \multirow[t]{6}{*}{$5 \mathrm{mg} / \mathrm{kg}$} & 62 & 23.4 & 23.3 & 23.5 & 24.3 & 24.4 & 24.2 & 24.8 & 24.4 & 25.4 & 25.4 & 26.0 \\
\hline & 63 & 27.2 & 27.2 & 27.4 & 27.8 & 28.0 & 28.0 & 29.0 & 28.6 & 30.4 & 29.6 & 30.0 \\
\hline & 64 & 22.7 & 23.2 & 23.4 & 24.1 & 24.0 & 24.4 & 24.8 & 24.8 & 25.6 & 25.6 & 26.0 \\
\hline & 65 & 23.0 & 24.0 & 24.0 & 24.8 & 24.6 & 24.8 & 25.4 & 25.0 & 25.6 & 26.2 & 26.6 \\
\hline & Mean & 23.9 & 24.0 & 24.1 & 24.5 & 24.6 & 24.7 & 25.5 & 25.2 & 26.1 & 26.0 & 26.5 \\
\hline & SE & 0.8 & 0.9 & 0.9 & 1.0 & 1.0 & 0.9 & 0.9 & 0.9 & 1.2 & 1.0 & 1.0 \\
\hline DTX & 66 & 23.2 & 23.5 & 23.0 & 23.9 & 24.6 & 24.6 & 25.0 & 24.4 & 25.4 & 25.2 & 25.1 \\
\hline \multirow[t]{6}{*}{$10 \mathrm{mg} / \mathrm{kg}$} & 67 & 22.6 & 22.2 & 22.7 & 23.4 & 23.0 & 23.6 & 23.6 & 23.0 & 23.6 & 23.8 & 23.4 \\
\hline & 68 & 26.5 & 26.0 & 26.0 & 26.9 & 26.6 & 26.8 & 27.0 & 24.6 & 23.8 & 23.6 & 22.8 \\
\hline & 69 & 23.1 & 23.2 & 23.3 & 24.2 & 24.6 & 25.0 & 25.0 & 25.2 & 25.4 & 25.4 & 25.6 \\
\hline & 70 & 25.2 & 25.0 & 25.2 & 25.8 & 26.2 & 26.4 & 26.4 & 25.4 & 26.2 & 25.6 & 25.4 \\
\hline & Mean & 24.1 & 24.0 & 24.0 & 24.8 & 25.0 & 25.3 & 25.4 & 24.5 & 24.9 & 24.7 & 24.5 \\
\hline & SE & 0.7 & 0.7 & 0.7 & 0.7 & 0.6 & 0.6 & 0.6 & 0.4 & 0.5 & 0.4 & 0.6 \\
\hline
\end{tabular}

Table VIb. Student's t-test (vs. vehicle).

T-TEST $v s$. Vehicle

Days

\begin{tabular}{|c|c|c|c|c|c|c|c|c|c|c|c|}
\hline & & & & & & & & & & & \\
\hline & 1 & 4 & 8 & 11 & 14 & 17 & 21 & 24 & 28 & 32 & 33.0 \\
\hline DTX $(0.1 \mathrm{mg} / \mathrm{kg})$ & 0.900 & 0.818 & 0.906 & 0.745 & 0.965 & 1.000 & 0.892 & 0.985 & 0.778 & 0.713 & 0.774 \\
\hline DTX $(0.5 \mathrm{mg} / \mathrm{kg})$ & 0.776 & 0.897 & 0.851 & 0.958 & 0.896 & 0.659 & 0.812 & 0.984 & 0.681 & 0.597 & 0.561 \\
\hline DTX (0.75 mg/kg) & 0.508 & 0.552 & 0.377 & 0.492 & 0.574 & 0.522 & 0.514 & 0.384 & 0.618 & 0.812 & 0.782 \\
\hline DTX $(1 \mathrm{mg} / \mathrm{kg})$ & 0.348 & 0.180 & 0.062 & 0.173 & 0.219 & 0.474 & 0.407 & 0.385 & 0.597 & 0.798 & 0.747 \\
\hline DTX $(2.5 \mathrm{mg} / \mathrm{kg})$ & 0.756 & 0.945 & 0.746 & 0.847 & 0.971 & 0.766 & 0.638 & 0.939 & 0.788 & 0.667 & 0.664 \\
\hline DTX $(5 \mathrm{mg} / \mathrm{kg})$ & 0.789 & 0.741 & 0.879 & 0.861 & 0.782 & 0.968 & 0.749 & 0.866 & 0.592 & 0.563 & 0.447 \\
\hline DTX $(10 \mathrm{mg} / \mathrm{kg})$ & 0.573 & 0.682 & 0.933 & 0.502 & 0.333 & 0.430 & 0.729 & 0.483 & 0.630 & 0.633 & 0.379 \\
\hline
\end{tabular}



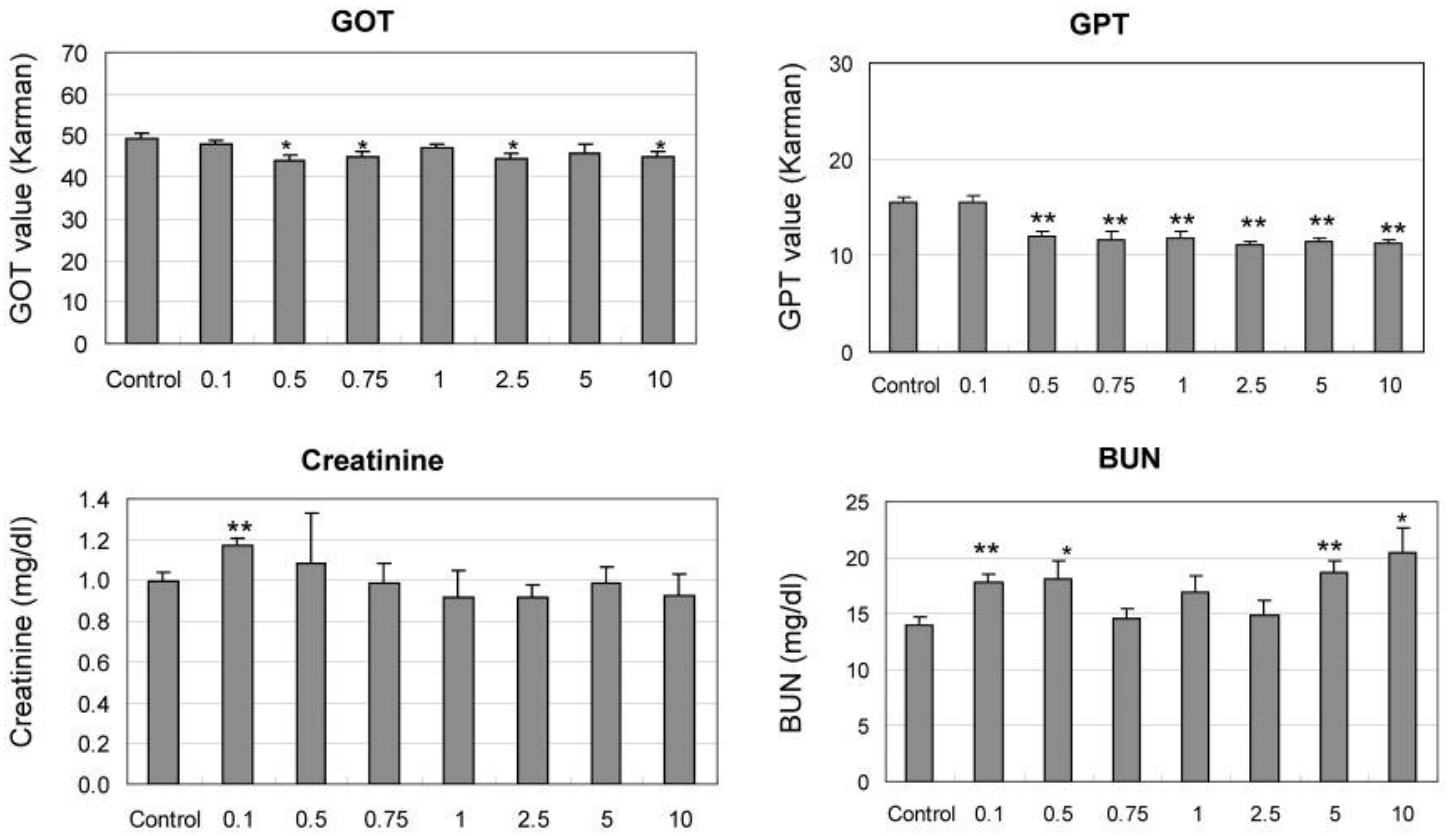

Figure 6. Average of plasma glutamic-oxaloacetic transaminase (GOT), glutamic-pyruvic transaminase (GPT), creatinine and blood urea nitrogen $(B U N)$ values in the blood of xenograft mice. Each value represents the mean \pm SE of five mice. $*$ and $* *$ indicate $p<0.05$ and 0.01 compared with control using Student's t-test. Each value was estimated with commercially available kits (see the Materials and Methods section for details).

with $2.5 \mathrm{mg} / \mathrm{kg}$ DTX. In many cases, mice with $2.5 \mathrm{mg} / \mathrm{kg}$ DTX developed tumor spheres filled with liquid, such as blood plasma and whole blood (Figure 3D), with tumor volume and body weight being higher. There is no precise explanation for this result except that DTX often causes edematous side-effects in clinical use (10). The body weights of mice at $10 \mathrm{mg} / \mathrm{kg}$ DTX were reduced one week after DTX administration, which was maintained until the end. This observation could be due to the toxicities of DTX.

Next, we estimated the inhibitory activities of DTX in xenograft mice developed by implantation of a solid tumor because the targets of DTX are usually solid tumors instead of individual cells (Figure 4). In this study, a wide range of DTX doses of $0.1,0.5,0.75,1,2.5,5$ and $10 \mathrm{mg} / \mathrm{kg}$ was subcutaneously administered once a week for 32 days and tumor volume, as well as body weights, were measured (Figure 4). The inhibitory effects of DTX at 5 and $10 \mathrm{mg} / \mathrm{kg}$ were the strongest (Figure $4 \mathrm{~A}$ and $\mathrm{B}$ ). Interestingly, the suppression effects at $2.5 \mathrm{mg} / \mathrm{kg}$ were less than those at $0.1 \mathrm{mg} / \mathrm{kg}$ and with vehicle. Edema-like effects were noted in most bodies of mice with $2.5 \mathrm{mg} / \mathrm{kg}$ DTX (Figure 4D), with tumors being filled with blood serum and other liquid products (Figures 3 and 5). Again, the only known explanation for these edema-like effects is the edema sideeffects observed in clinical patients with the administration of DTX $(5,10)$. The inhibitory activities in xenograft mice with solid tumors were weaker than for individual DU145 cells in Matrigel ${ }^{\mathrm{TM}}$ (Figures 3 and 4). This difference is thought to be due to the difficulty to penetrate the solid DU145 tumor (Figure 2B).

The body weights of mice with the solid tumor model were also suppressed by the administration of $10 \mathrm{mg} / \mathrm{kg}$ DTX after 20 days (Figure 4C). However, the weights of the body, liver and kidney on the final day nearly matched the control levels (Figure 5). Hypertrophy of the spleen was frequently noted in all conditions and its dose-dependence was unclear (Figure 5). This could be an artificial result attributed to subcutaneous wounding of nude mice because this phenomenon has not been clinically reported. With respect to hematological parameters, the plasma GOT and GPT values were significantly low, except for with $0.1 \mathrm{mg} / \mathrm{kg}$ DTX (Figure 6). These significant decreases did not indicate liver toxicity because the values are usually increased in toxic conditions. Plasma creatinine was normal under all conditions, while its value was only higher at the lowest dose (Figure 6); the plasma BUN values were significantly higher (Figure 6). Although an increase in the BUN is reported in the interview form on DTX (5), we do not have an explanation for this observation. The body weights of mice at a dose of $10 \mathrm{mg} / \mathrm{kg}$ were clearly suppressed for both xenograft models (Figure 3C and $4 \mathrm{C}$ ), with this effect being suspected to be a toxic sideeffect of DTX.

In conclusion, we performed a systematic trial on the inhibitory activities of DTX in two DU145 xenograft models 
(Figure 2) and demonstrated that (i) DTX was more effective in the xenograft model formed by DU145 cell implantation than the model formed by solid DU145 tumor implantation (Figures 3 and 4); (ii) administration of $2.5 \mathrm{mg} / \mathrm{kg}$ DTX was critical because the inhibitory activities of $2.5 \mathrm{mg} / \mathrm{kg}$ DTX and lower were weak, while DTX showed effective inhibitory activities at 5 and $10 \mathrm{mg} / \mathrm{kg}$; (iii) edema-like effects were observed for both xenograft models at $2.5 \mathrm{mg} / \mathrm{kg}$ DTX with no clear explanation for this irregularity; and (iv) suppression of body weight gain was observed with $10 \mathrm{mg} / \mathrm{kg}$ DTX in both xenograft models. DTX is now a standard anti-cancer drug for first-line treatment of hormone-refractory prostate cancer cells. However, its clinical prescription is sometimes limited by edematous side-effects, causing, occasionally, severe edema $(5,11)$. Based on these results, we believe that the $2.5 \mathrm{mg} / \mathrm{kg}$ DTX dose was critical in the xenograft model of DU145 tumor growth for evaluating anti-tumor effects and adverse events regarding combination treatments of new compounds leading, eventually, to a better selection of novel hormone-independent prostate cancer agents.

\section{Acknowledgements}

This research was supported in part by JSPS KAKENHI Grant Numbers 26460164 and 15K08036 and by the Japan Agency for Medical Research and Development.

\section{References}

1 DeFrancesco L: Prostate cancer prevention trial launched. Nat Medicine 7: 1076, 2001.

2 PDQ Adult Treatment Editorial Board. Prostate Cancer Treatment (PDQ $\left.{ }^{\circledR}\right)$ : Health Professional Version. https:// www.cancer.gov/publications/pdq.

3 Petrylak DP, Macarthur RB, O'Connor J, Shelton G, Judge T, Balog J, Pfaff C, Bagiella E, Heitjan D, Fine R, Zuech N, Sawczuk I, Benson M and Olsson CA: Phase I trial of docetaxel with estramustine in androgen-independent prostate cancer. J Clin Oncol 17: 958-967, 1999.
4 Tsakalozou E, Eckman AM and Bae Y: Combination effects of docetaxel and doxorubicin in hormone-refractory prostate cancer cells. Biochem Res Internatl 2012: 10, 2012.

5 Japanese interview form for docetaxel (A Japanese official PMDA website. http://www.info.pmda.go.jp/go/interview/ 1/780069_4240405A1037_1_011_1F). Sanofi website for docetaxel (http://pk.sanofi-aventis.com/products/TaxotereNew.pdf)

6 Kaya AO, Buyukberber S, Coskun U, Yildiz R, Ozturk B, Yaman E, Adisen E, Gureli M and Benekli M: Acute erythema and edematous skin reaction and ectropion following docetaxel in a patient with non-small cell lung cancer. Cutan Ocul Toxicol 27: 327-331, 2008.

7 Ikezoe T, Hisatake Y, Takeuchi T, Ohtsuki Y, Yang Y, Said JW, Taguchi H and Koeffler HP: HIV-1 protease inhibitor, ritonavir: A potent inhibitor of CYP3A4, enhanced the anticancer effects of docetaxel in androgen-independent prostate cancer cells in vitro and in vivo. Cancer Res 64: 7426-7431, 2004.

8 Hwang JJ, Kim YS, Kim T, Kim MJ, Jeong IG, Lee JH, Choi J, Jang S, Ro S and Kim CS: A novel histone deacetylase inhibitor, CG200745, potentiates anticancer effect of docetaxel in prostate cancer via decreasing Mcl-1 and Bcl-XL. Invest New Drugs 30: 1434-1442, 2012.

9 Bissery MC, Guénard D, Guéritte-Voegelein F and Lavelle F: Experimental antitumor activity of taxotere (RP 56976, NSC 628503), a taxol analogue. Cancer Res 51: 4845-4852, 1991.

10 Béhar A, Pujade-Lauraine E, Maurel A, Brun MD, Chauvin FF, Feuilhade de Chauvin F, Oulid-Aissa D and Hille D: The pathophysiological mechanism of fluid retention in advanced cancer patients treated with docetaxel, but not receiving corticosteroid comedication. Br J Clin Pharmacol 43: 653-658, 1997.

11 Picus J and Schultz M. Docetaxel (Taxotere) as monotherapy in the treatment of hormone-refractory prostate cancer: Preliminary results. Semin Oncol 5(Suppl 17): 14-18, 1999. 